\title{
Characterization of atmospheric bioaerosols along the transport pathway of Asian dust during the Dust-Bioaerosol 2016 Campaign
}

\author{
Kai Tang ${ }^{1}$, Zhongwei Huang ${ }^{1}$, Jianping Huang ${ }^{1}$, Teruya Maki ${ }^{2}$, Shuang Zhang ${ }^{1}$, Atsushi Shimizu ${ }^{3}$, Xiaojun Ma ${ }^{1}$, \\ Jinsen Shi ${ }^{1}$, Jianrong $\mathrm{Bi}^{1}{ }^{1}$, Tian Zhou ${ }^{1}$, Guoyin Wang ${ }^{1}$, and Lei Zhang ${ }^{1}$ \\ ${ }^{1}$ Key Laboratory for Semi-Arid Climate Change of the Ministry of Education, College of Atmospheric Sciences, \\ Lanzhou University, Lanzhou, 730000, China \\ ${ }^{2}$ College of Science and Engineering, Kanazawa University, Kakuma, 920-1192, Japan \\ ${ }^{3}$ National Institute for Environmental Studies, Tsukuba, 305-8506, Japan
}

Correspondence: Zhongwei Huang (huangzhongwei@1zu.edu.cn)

Received: 13 December 2017 - Discussion started: 18 December 2017

Revised: 16 April 2018 - Accepted: 30 April 2018 - Published: 24 May 2018

\begin{abstract}
Previous studies have shown that bioaerosols are injected into the atmosphere during dust events. These bioaerosols may affect leeward ecosystems, human health, and agricultural productivity and may even induce climate change. However, bioaerosol dynamics have rarely been investigated along the transport pathway of Asian dust, especially in China where dust events affect huge areas and massive numbers of people. Given this situation, the DustBioaerosol (DuBi) Campaign was carried out over northern China, and the effects of dust events on the amount and diversity of bioaerosols were investigated. The results indicate that the number of bacteria showed remarkable increases during the dust events, and the diversity of the bacterial communities also increased significantly, as determined by means of microscopic observations with 4,6diamidino-2-phenylindole (DAPI) staining and MiSeq sequencing analysis. These results indicate that dust clouds can carry many bacteria of various types into downwind regions and may have potentially important impacts on ecological environments and climate change. The abundances of DAPI-stained bacteria in the dust samples were 1 to 2 orders of magnitude greater than those in the non-dust samples and reached $10^{5}-10^{6}$ particles $\mathrm{m}^{-3}$. Moreover, the concentration ratios of DAPI-stained bacteria to yellow fluorescent particles increased from $5.1 \% \pm 6.3 \%$ (non-dust samples) to $9.8 \% \pm 6.3 \%$ (dust samples). A beta diversity analysis of the bacterial communities demonstrated the distinct clustering of separate prokaryotic communities in the dust and non-dust samples. Actinobacteria, Bacteroidetes, and Proteobacteria
\end{abstract}

remained the dominant phyla in all samples. As for Erenhot, the relative abundances of Acidobacteria and Chloroflexi had a remarkable rise in dust events. In contrast, the relative abundances of Acidobacteria and Chloroflexi in non-dust samples of R-DzToUb were greater than those in dust samples. Alphaproteobacteria made the major contribution to the increasing relative abundance of the phylum Proteobacteria in all dust samples. The relative abundance of Firmicutes did not exceed $5 \%$ in all the air samples, even though it is the predominant phylum in the surface sand samples from the Gobi Desert. These results illustrate that the bacterial community contained in dust aerosol samples has a different pattern compared with non-dust aerosol samples, and the relative abundances of airborne bacteria are different from those in the surface sand or soil and differ by location and transmitting vector.

\section{Introduction}

Bioaerosols are a class of atmospheric particles that range in size from nanometers up to about a tenth of a millimeter. They are made up of living and dead organisms (e.g., algae, archaea, and bacteria), dispersal units (e.g., fungal spores and plant pollen), and various fragments or excretions (e.g., plant debris and brochosomes; Fröhlich-Nowoisky et al., 2016). Several studies have investigated the role of dust events as a vehicle for bioaerosols (Hervàs et al., 2009; Prospero et al., 2005; Sugimoto et al., 2012; Yamaguchi et al., 2012). Asian 


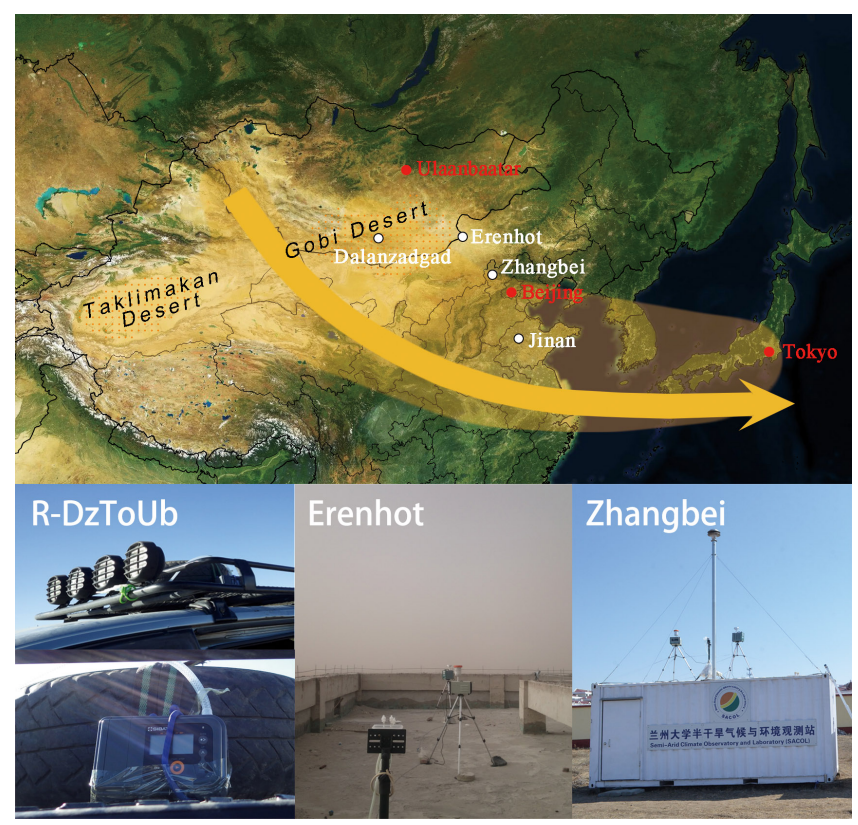

Figure 1. The design of the Dust-Bioaerosol Campaign 2016, the locations of the sampling sites, and the contexts of the bioaerosol samplers (R-DzToUb is located along the road between Dalanzadgad and Ulaanbaatar).

dust events are capable of moving masses of soil-derived dust over long distances and may introduce large amounts of microorganisms and pollen to the atmosphere. It is well known that Asian dust frequently disperses all around East Asian regions (Iwasaka et al., 1983; Huang et al., 2008a, 2010) and can even reach the Americas (Husar et al., 2001) and the Arctic (Huang et al., 2015). Asian dust clouds can sometimes be transported more than one full circuit around the globe in approximately 13 days (Uno et al., 2009), and Asian dust has been identified in ice and snow cores from Greenland (Bory et al., 2003) and the French Alps (Grousset et al., 2003). Drylands are one of the most sensitive areas to climate change and human activities, and the increasing aridity, enhanced warming, and rapidly growing human population will exacerbate the risk of land degradation and desertification in the near future in the drylands (Huang et al., 2015, 2017a, b).

Increasing evidence shows that microbes are transported by Asian dust events (Hua et al., 2007; Maki et al., 2017; Yeo and Kim, 2002). In Japan, the concentrations of bacterial cells and the structure of airborne bacterial communities in the near-surface air and the free troposphere are affected by Asian dust events (Maki et al., 2014, 2015). Similarly, the yellow sandstorms that originate in Asian deserts have been reported to affect the ambient air quality of Taiwan by increasing the levels of fungal spores (Ho et al., 2005; Wu et al., 2004). Results from South Korea also show that Asian dust impacts both airborne fungal concentrations and fungal communities (Jeon et al., 2011, 2013; Yeo and Kim, 2002).
Considering the transoceanic and transcontinental dispersal of bioaerosols associated with dust events, the importance of bioaerosols in the atmosphere is likely to be seriously underestimated. These bioaerosols may affect leeward ecosystems, human health, and agricultural productivity, and they may play a larger role in the climate system by acting as efficient ice nucleating particles and cloud condensation nuclei. Certain species of bacteria and fungi are known to have very high ice nucleating (IN) ability, especially at warmer temperatures (Maki and Willoughby, 1978), potentially leading to the initiation of ice formation in clouds and thereby influencing precipitation, cloud dynamics, and the amount of incoming and outgoing solar radiation (Creamean et al., 2013). A study used a cloud simulation chamber to demonstrate that bacterial IN activity is maintained even after cell death (Amato et al., 2015). Hence, the role of microorganisms in the atmosphere is an underappreciated aspect of biological and atmospheric science; these microorganisms have potentially important impacts on the hydrological cycle, clouds, and climate (DeLeon-Rodriguez et al., 2013).

Moreover, bioaerosols may have a significant influence on human health and the spread of plant diseases. Airborne microorganisms containing bacteria, fungi, and viruses can have infectious, allergenic, or toxic effects on living organisms, causing disease or allergies in humans, agricultural crops, livestock, and ecosystems, including coral reefs. The dust-event-driven dispersal of bioaerosols is strongly correlated with allergen burdens and asthma (Griffin, 2007; Ichinose et al., 2005; Liu et al., 2014). The long-distance aerial dispersal of pathogens by the wind can spread plant diseases (Brown and Hovmøller, 2002) and human diseases, such as Kawasaki disease (Jorquera et al., 2015; Rodo et al., 2011).

Therefore, information on the abundance of bioaerosols in the dust is necessary to assess the influence of these bioaerosols on public health, ecosystems, biogeographical distributions, and meteorological and climatic processes (Hara and Zhang, 2012). Recent research has shown that the Gobi Desert, instead of the Taklimakan Desert, plays the most important role in contributing to dust concentrations in East Asia, and approximately $35 \%$ of the dust emitted from the Gobi Desert is transported to remote areas in East Asia in spring (Chen et al., 2017). To investigate the effects of dust events from the Gobi Desert on the amount and diversity of microbes in the air, the Dust-Bioaerosol (DuBi) Campaign was carried out during March through May in 2016. This campaign is called "DuBi-2016" in this paper (Fig. 1).

In the DuBi-2016 Campaign, air sampling was performed continuously at three sites downwind of the Gobi Desert. These sites lie along the transport path of Asian dust, which were Erenhot, Zhangbei, and Jinan. Frequent dust storms attacked Erenhot directly, and a great amount of transported dust was observed there. Only a small amount, by contrast, could arrive in Zhangbei and Jinan. In addition, some samples were collected on the road between Dalanzadgad and Ulaanbaatar, and these samples enable the comparison of the 
Table 1. Information on the sampling sites.

\begin{tabular}{|c|c|c|c|c|c|}
\hline Location & $\begin{array}{l}\text { Latitude }\left({ }^{\circ} \mathrm{N}\right) \text { and } \\
\text { longitude }\left({ }^{\circ} \mathrm{E}\right)\end{array}$ & $\begin{array}{l}\text { Altitude } \\
\left(\mathrm{ASL}^{\mathrm{a}}\right)\end{array}$ & $\begin{array}{l}\text { Sampling height } \\
\left(\mathrm{AGL}^{\mathrm{b}}\right)\end{array}$ & $\begin{array}{l}\text { Sampling period } \\
\text { (yyyy/mm/dd) }\end{array}$ & $\begin{array}{l}\text { Sampling } \\
\text { duration }\end{array}$ \\
\hline Erenhot & ER: $43.668,111.953$ & $957 \mathrm{~m}$ & $\begin{array}{l}20 \mathrm{~m} \\
\text { (on a building) }\end{array}$ & $2016 / 03 / 30-2016 / 05 / 20$ & $2-24 \mathrm{~h}$ \\
\hline Zhangbei & ZB: $41.156,114.701$ & $1395 \mathrm{~m}$ & $\begin{array}{l}4 \mathrm{~m} \\
\text { (on a container) }\end{array}$ & 2016/03/29-2016/05/31 & $2-16 \mathrm{~h}$ \\
\hline Jinan & JN: $36.673,117.057$ & $48 \mathrm{~m}$ & $\begin{array}{l}25 \mathrm{~m} \\
\text { (on a building) }\end{array}$ & 2016/03/23-2016/06/04 & $10-14 \mathrm{~h}$ \\
\hline R-DzToUb & $\begin{array}{l}\text { Dz: } 43.557,104.419 \\
\text { Ub: } 47.886,106.906\end{array}$ & $\begin{array}{l}\text { Dz: } 1489 \mathrm{~m} \\
\text { Ub: } 1302 \mathrm{~m}\end{array}$ & $\begin{array}{l}2 \mathrm{~m} \\
\text { (on a car) }\end{array}$ & $2016 / 05 / 05$ & $1 \mathrm{~h}$ \\
\hline
\end{tabular}

${ }^{\text {a }}$ ASL: above sea level. ${ }^{\mathrm{b}}$ AGL: above ground level

structure of microbial communities between the source and downwind regions. By combining microscopy and MiSeq sequencing analysis (Illumina, CA, USA), the potential effects of long-range-transported dust on the amount and diversity of bioaerosols can be well characterized.

\section{Experiments}

\subsection{Sample collection}

Information on the sampling sites is provided in Table 1. The sampling sites in Erenhot and Zhangbei were located to the northwest of the residential area and at a distance from this area. Anthropogenic activities that might influence the sites were not expected in cases in which air masses arrive from the south, southwest, west, or northwest. Therefore, the dust particles appearing at the sites had traveled long distances in the atmosphere and originated primarily in Mongolia and northern China. In addition, five bioaerosol samples were collected on the car along the road between Dalanzadgad and Ulaanbaatar (R-DzToUb). These samples represent conditions in the dust source regions.

The bioaerosol samples were collected using four sterilized polycarbonate filters with a pore size of $0.2 \mu \mathrm{m}$ (Whatman 111106) with a sterilized Swinnex $13 \mathrm{~mm}$ filter holder (Millipore SX0001300) connected to an air pump (AS ONE, MAS-1, Japan; the flow rate for each filter was approximately $0.3 \mathrm{~L} \mathrm{~min}^{-1}$ ) for $1-24 \mathrm{~h}$, according to air quality conditions. Whenever dust arrived, intensive observations were made to obtain information on the fine structure of the dust event. Before sampling, all the filters were sterilized by autoclaving $\left(121^{\circ} \mathrm{C}\right.$ for $\left.20 \mathrm{~min}\right)$. After sampling, the samples were stored at $-80^{\circ} \mathrm{C}$ until the downstream analyses were performed.

To avoid contamination, the sampling filter holders and the materials used to change the filters were treated with $75 \%$ ethanol every day, and a mask was worn during operation. Detailed information on the samples is provided in Tables S1, S2, and S3 in the Supplement.

\subsection{Meteorological data and aerosol information}

In Erenhot, a device (T\&D Corporation, TR-74Ui, Japan) was used to measure the temperature, relative humidity, illuminance, and UV intensity sequentially. Data describing the attenuated backscatter coefficient, the volume depolarization ratio, and the color ratio were obtained from the Zamyn-Üüd observation site of AD-Net $\left(43.72^{\circ} \mathrm{N}\right.$, $111.90^{\circ} \mathrm{E} ; 962 \mathrm{~m}$ a.s.l.), which is located less than $10 \mathrm{~km}$ away from the sampling site in Erenhot (Nishizawa et al., 2016; Shimizu et al., 2016).

In Zhangbei, basic meteorological information, including measurements of temperature, relative humidity, pressure, wind, precipitation, and radiation, was gathered by an automatic meteorological station (weather transmitter WXT520, Vaisala), and the $\mathrm{PM}_{2.5}$ mass concentrations were measured using a continuous ambient particulate $\mathrm{TEOM}^{\mathrm{TM}}$ monitor (series 1400a, Thermo Fisher Scientific Inc.; Huang et al., 2008b; Wang et al., 2010).

Using the National Oceanic and Atmospheric Administration Hybrid Single Particle Lagrangian Integrated Trajectory (HYSPLIT) model (http://www.arl.noaa.gov/HYSPLIT.php; last access: 18 September 2017), $72 \mathrm{~h}$ backward trajectories of the air masses at the Zhangbei observational site were calculated.

\subsection{Sample analysis}

The total number of microorganisms in the bioaerosols was determined by a modified counting method that was previously described by Maki et al. (2014). The samples were stained with $10 \mu \mathrm{g} \mathrm{mL}^{-1}$ 4,6-diamidino-2-phenylindole (DAPI, D9542, Sigma; the DAPI-DNA complex has an excitation wavelength of $364 \mathrm{~nm}$ and an emission wavelength of $454 \mathrm{~nm}$ ) for $15 \mathrm{~min}$ after being fixed in a $4 \%$ paraformaldehyde solution for $1 \mathrm{~h}$. The filter was then placed on a slide in a drop of low-fluorescence immersion oil (IMMOIL-F30CC, Olympus). A second drop of oil was added, and a coverslip was placed on top. Next, the prepared slides were observed using an epifluorescence microscope (BX53 and 
DP72, Olympus, Japan) equipped with an ultraviolet excitation system; an excitation waveband of 340-390 nm was used. Fluorescent particles with four different colors, blue, white, yellow, and black, were counted in 10 randomly selected fields. The fluorescent particle concentrations in the bioaerosols were calculated using the following formula:

$C=\frac{S_{1} \times N_{0}}{S_{0} \times V}$,

where $C$ is the number of fluorescent particles in the bioaerosols (particles $\mathrm{m}^{-3}$ ), $S_{1}$ is filtration area on the membrane $\left(7 \times 10^{7} \mu \mathrm{m}^{2}\right), S_{0}$ is the area of each microscopic field $\left(1.46 \times 10^{4} \mu \mathrm{m}^{2}\right), N_{0}$ is the average number of fluorescent particles in the microscopic field, and $V$ is the volume of the filtered sample $\left(\mathrm{m}^{3}\right)$. The detection limit of the particles is approximately $1.0 \times 10^{4}$ particles $\mathrm{m}^{-3}$ of air.

\subsection{DNA extraction, sequencing, and phylogenetic analysis}

The genomic DNA (gDNA) was extracted from the atmospheric samples from Erenhot and Mongolia using the phenol chloroform extraction-ethanol precipitation method (Maki et al., 2017). Two-step PCR amplification and product purification were then carried out according to the method of Maki et al. (2017). Two-step PCR has several advantages, such as increased reproducibility and the recovery of greater levels of genetic diversity during amplicon sequencing (Park et al., 2016). During the first step of PCR amplification, fragments of $16 \mathrm{~S}$ rDNA (which covers the variable region V4) were amplified from the extracted gDNA using the universal bacterial primers 515F ( $5^{\prime}$-Seq A-TGTGCCAGCMGCCGCGGTAA$\left.3^{\prime}\right)$ and 806R (5'-Seq B-GGACTACHVGGGTWTCTAAT3'; Caporaso et al., 2011); Seq A and Seq B represent the nucleotide sequences bounded by the primer sets in the second step of PCR. The detailed process has been described by Maki et al. (2017). An Illumina MiSeq sequencing system (Illumina, CA, USA) and a MiSeq Reagent Kit V2 (Illumina, CA, USA) were used to perform the sequencing, and an average read length of $270 \mathrm{bp}$ was obtained. All the data obtained from MiSeq sequencing have been deposited in the DDBJ/EMBL/GenBank database, and the accession number of the submission is PRJNA413598.

The R software package (version 3.4.1) was employed to analyze the experimental data. The "phyloseq" package (version 1.20.0) was used to handle and analyze the highthroughput sequencing data. The Shannon index $\left(H^{\prime}\right)$ and the Simpson index (D) are calculated as follows:

$$
\begin{aligned}
& H^{\prime}=-\sum_{i=1}^{S} P_{i} \cdot \log _{2} P_{i}, \\
& D=1-\sum_{i=1}^{S}\left(P_{i}\right)^{2}
\end{aligned}
$$

where $S$ is the number of operational taxonomic units (OTUs), and $P_{i}$ is the relative proportion of an individual species $i$.

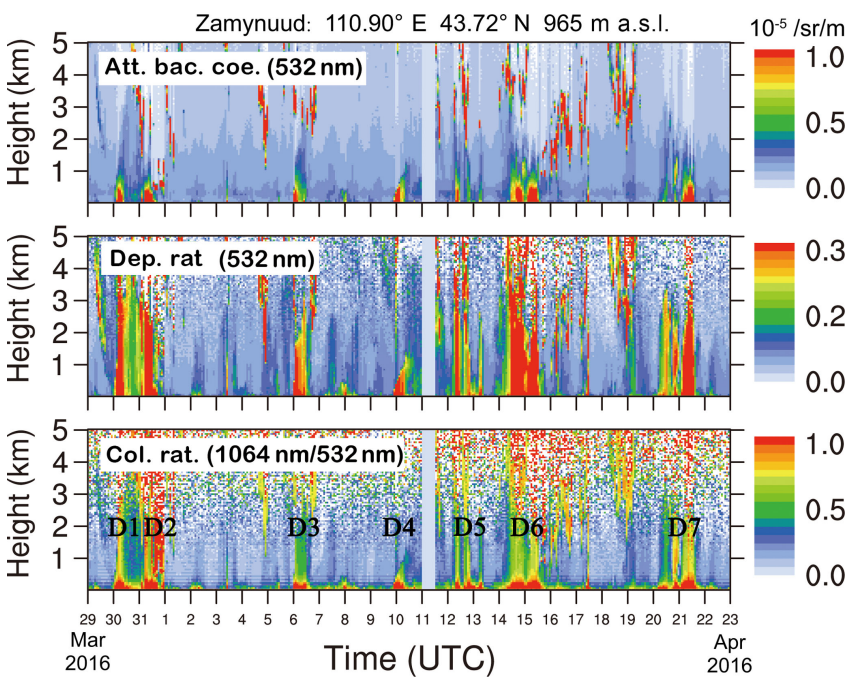

Figure 2. Lidar observations in Zamynuud during the sampling period. D1-D7 represent dust events that occurred in Erenhot.

Principal coordinate analysis (PCoA) with weighted UniFrac distances was used to explore and visualize similarities or dissimilarities of the bacterial communities contained in samples. UniFrac measures the difference between two collections of sequences as the amount of evolutionary history that is unique to either of the two, which is measured as the fraction of branch length in a phylogenetic tree that leads to descendants of one sample or the other but not both (Lozupone et al., 2011). There are two phylogenetic measures of community $\beta$ diversity: unweighted UniFrac, a qualitative measure that uses only the presence or absence of data, and weighted UniFrac, a quantitative measure that uses the abundance of each taxon (Lozupone et al., 2007). UniFrac, coupled with standard multivariate statistical techniques including principal coordinate analysis ( $\mathrm{PCoA}$ ), can be used to cluster many samples according to the difference in their bacterial communities.

\section{Results and discussion}

\subsection{Identification of the dust events}

The dust events in spring 2016 were identified from lidar observations in Zamynuud and $\mathrm{PM}_{2.5}$ mass concentrations in Zhangbei. In addition, meteorological factors, such as atmospheric pressure, wind speeds, and wind directions, were checked to confirm the dust events in Zhangbei. Polarization measurements from lidar remote sensing are very useful to identify the dust events from others (Zhou et al., 2013; Sugimoto and Huang, 2014). The attenuated backscattering coefficient at $532 \mathrm{~nm}$ (att. bac. coe.), the volume depolarization ratio (dep. rat.) and the color ratio (col. rat.) increased dramatically when the dust events occurred. Seven heavy dust events (D1-D7) occurred in Erenhot during the sampling 


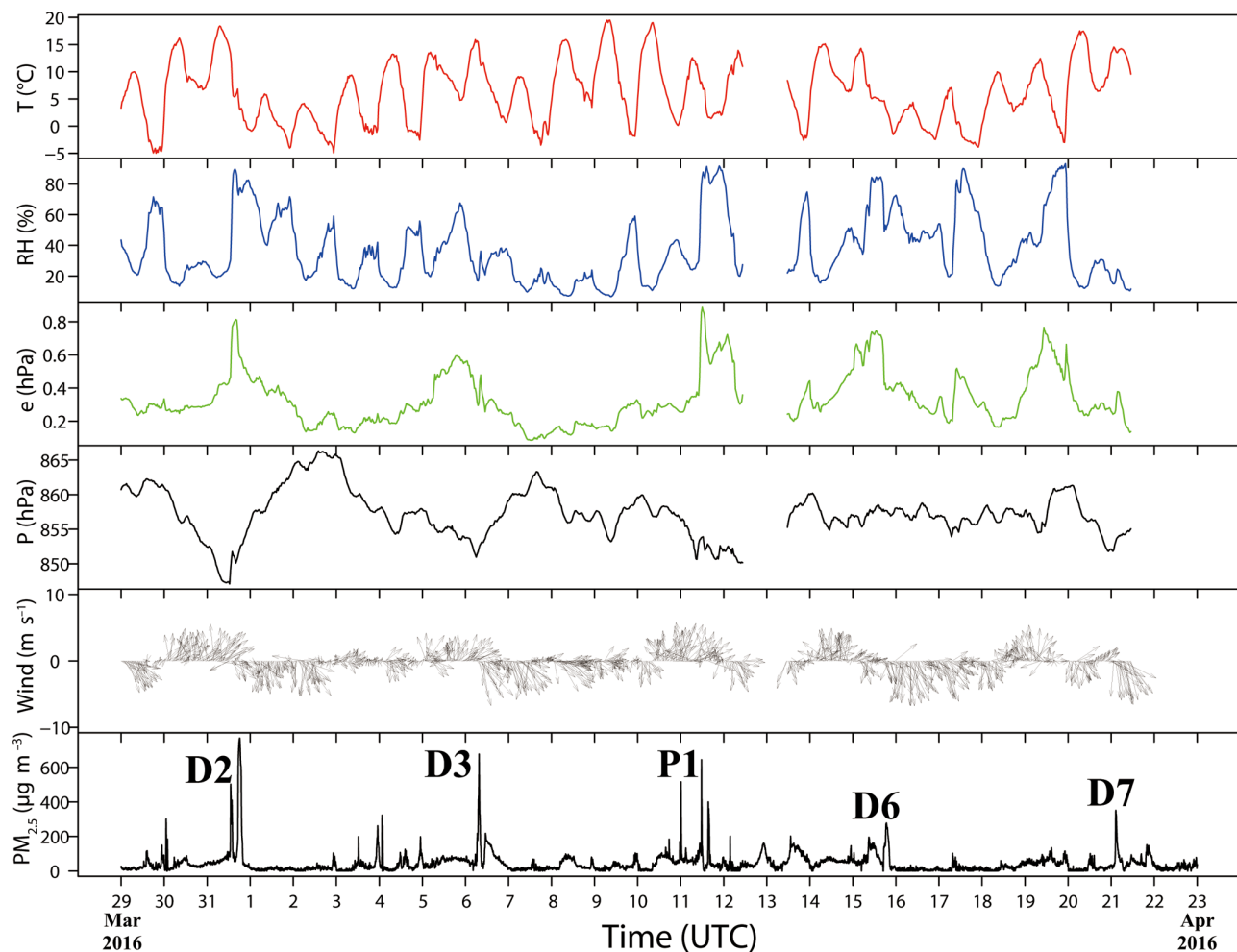

Figure 3. Meteorological conditions and air quality measurements during the sampling period. $T$ : temperature; RH: relative humidity; $e$ : water vapor pressure; $P$ : atmospheric pressure. D1-D7 correspond to the seven dust events that occurred in Erenhot.
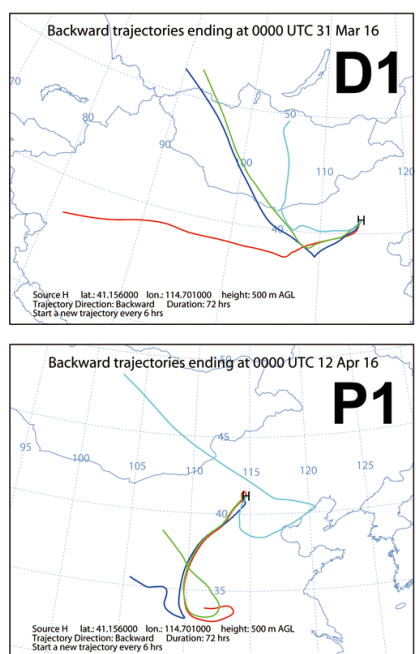
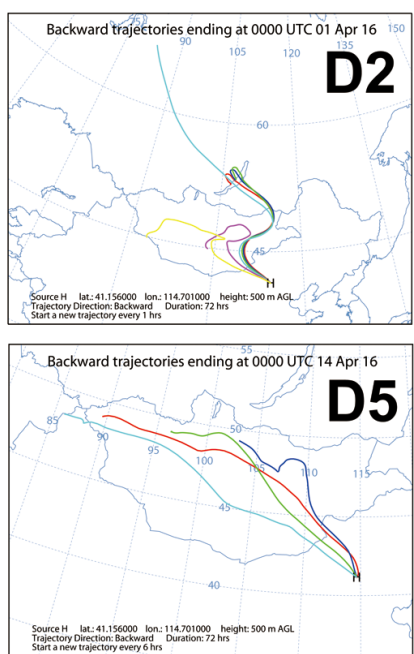
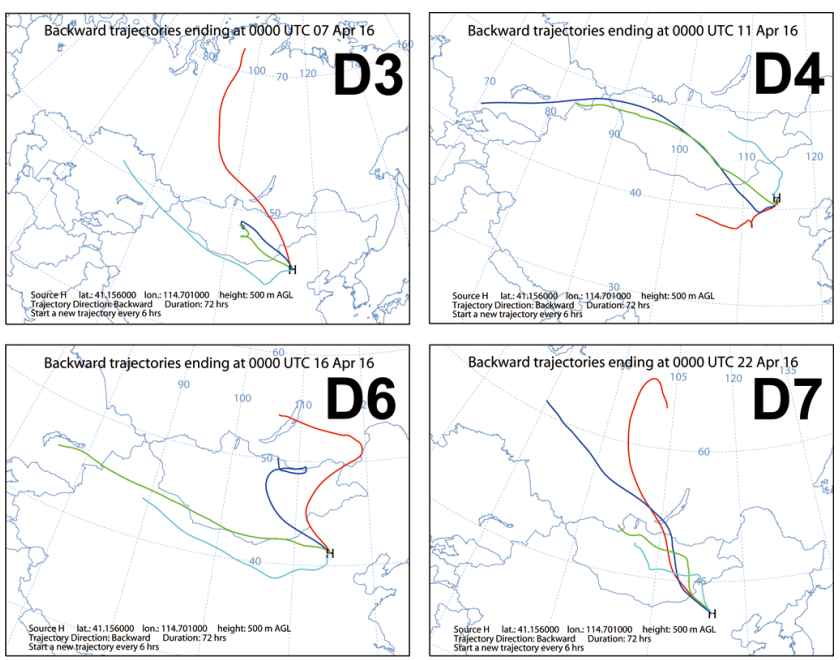

Figure 4. The $72 \mathrm{~h}$ back trajectories of air masses in Zhangbei calculated using the HYSPLIT model. D1-D7 represent the dust events that occurred in Erenhot.

period (Fig. 2). Accordingly, the samples collected during events D1-D7 were named "dust samples" (Table S1). During events D2, D3, and D7, the mass concentrations of $\mathrm{PM}_{2.5}$ in Zhangbei increased significantly with northwest or north winds, increasing wind speed, and an apparent decline in atmospheric pressure (Fig. 3). These observations indicate that dust events occurred in Zhangbei at that time. A slight in- crease in $\mathrm{PM}_{2.5}$ mass concentrations was observed during event D6, accompanied by a strong north wind and relatively stable atmospheric pressure, indicating that Zhangbei was slightly affected by the dust event that occurred in Erenhot at that time. Accordingly, samples ZB3_31N, ZB4_6D, ZB4_6N, and ZB4_21D were considered as "dust samples" (Table S2). The $72 \mathrm{~h}$ back trajectories of air masses in Zhang- 


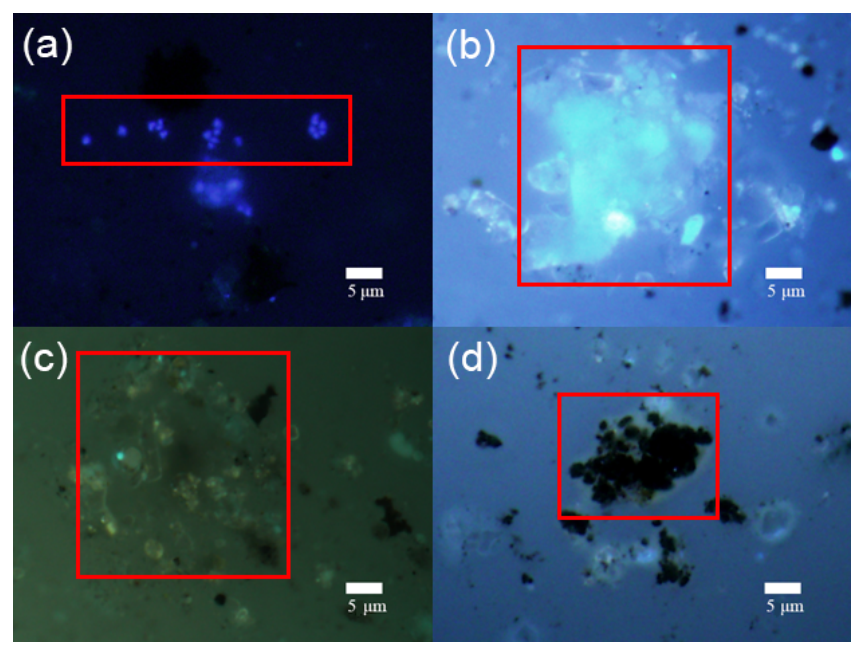

Figure 5. Epifluorescence micrograph of (a) DAPI-stained bacteria (with diameters $<3 \mu \mathrm{m}$ ), (b) white particles (mineral particles), (c) yellow particles (organic matter), and (d) black particles (black carbon) in air samples. All photomicrographs were taken at a magnification of $\times 1000$.

bei calculated using the HYSPLIT model indicate that dust events D2, D3, D6, and D7 originated in the Gobi Desert and passed over Erenhot and Zhangbei during the transport process. Several peaks in $\mathrm{PM}_{2.5}$ concentrations appeared in Zhangbei on 30 March and 4 and 11 April. These peaks were not dust events, as determined using the wind speeds, wind directions, and $72 \mathrm{~h}$ back trajectories (Figs. 3 and 4). An air pollution event named "P1" occurred on 11 April that was characterized by high $\mathrm{PM}_{2.5}$ concentrations, strong south winds, and air masses that originated in the southern regions (Fig. 4).

\subsection{State of the bioaerosols in the dust and non-dust samples}

Under microscopic observation, the particles stained with DAPI emitted several types of fluorescence, mainly blue, white, yellow, and black fluorescence (Fig. 5), which were thus categorized as DAPI-stained bacteria (with diameters $<3 \mu \mathrm{m}$ ), white particles (mineral particles), yellow particles (organic matter), and black particles (black carbon), respectively (Maki et al., 2017). There were a lot of yellow particles in dust samples, while black particle concentrations increased in the samples collected on heavy air pollution days. The internal and external mixing between dust particles and black carbon were observed under the microscope (Fig. S4 in the Supplement). Some research shows that dust aerosols and anthropogenic pollutant particles (black carbon) can be clearly distinguished depending on optical and radiative characteristics (Bi et al., 2016, 2017; Huang et al., 2011; Pu et al., 2015; Wang et al., 2014, 2015, 2018). Hence, the further assessment of the radiative effects of mixed-type aerosols is warranted.

Analysis of the microphotographs shows that the dust and non-dust samples were significantly different. As two examples, ER4_12D was compared with ER4_13, and ER4_15D1 was compared with ER4_16. Compared with the sample ER4_16, which was collected during a non-dust event, the dust sample ER4_15D1 contained a surprising number of DAPI-stained bacteria (coccoid- or bacillus-like bacteria; Fig. $6 \mathrm{a}$ and $\mathrm{b}$ ). This comparison clearly demonstrates that dust events can carry large amounts of bacteria into the atmosphere, and these microbes continue to float towards downwind regions. We also take the dust events that occurred on 12 and 13 April as another example. These events differed somewhat from each other in terms of their dust intensity and dust blowing height. The lidar data clearly demonstrate that the dust mass noted on 12 April fell to the ground from nearly $4 \mathrm{~km}$, whereas the dust event that occurred on 13 April was mild by contrast and likely originated from a local source. Sample ER4_12D contained more DAPI-stained bacteria, although the sampling duration was shorter than that for sample ER4_13 (Fig. 6c and d). This result illustrates the fact that dust transported over long distances contained large amounts of microorganisms and may have substantial impacts on downwind regions. In addition, epifluorescence microscopy has revealed that aerosols collected at $800 \mathrm{~m}$ over the Taklimakan Desert contain large particles attached with microorganisms, such as bacteria (Maki et al., 2008). Airborne microbes are often attached to larger particles, especially yellow particles, and found as agglomerates (Tong and Lighthart, 2000), which may help them survive nutrient shortages and UV radiation and may even facilitate the growth and reproduction of the microbes.

Under the SEM, the bioaerosols displayed various states (Fig. 7). Spiny fungal spores (Fig. 7a) and shriveled pollen (Fig. 7d) may represent strategies that organisms take to protect themselves from the harsh atmospheric environment and ensure their survival. Entering a non-dividing state (dormancy) in which they transform morphologically to spores or undergo other cell wall modifications and slow down or stop their metabolic activity can improve their resistance to physical stresses, such as desiccation and UV radiation, which increases their chances of survival in the atmosphere (Smets et al., 2016). Furthermore, some coccus-like airborne microbes were found attached to mineral particles (Fig. 7e and f), which may serve as shelters and favor the survival of the bacteria. Interestingly, exocytosis or endocytosis (Fig. 7c) and cell division processes (Fig. 7b) were captured, showing that microbial activity proceeds in the air.

\subsection{Variations in the concentrations of fluorescent particles in the dust and non-dust samples}

When Asian dust events occurred in the downwind area, airborne microbial abundances increased 10- or 100-fold (Hara 
(a)
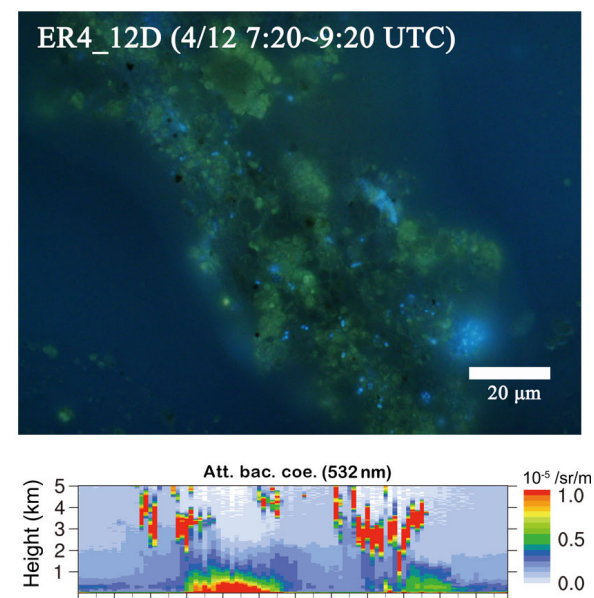

Dep. rat $(532 \mathrm{~nm})$

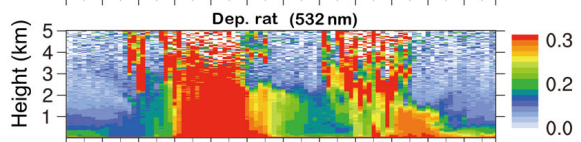

Col. rat. $(1064 \mathrm{~nm} / 532 \mathrm{~nm})$

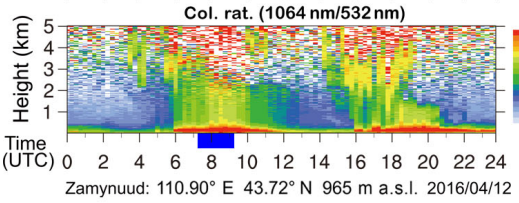

(c)
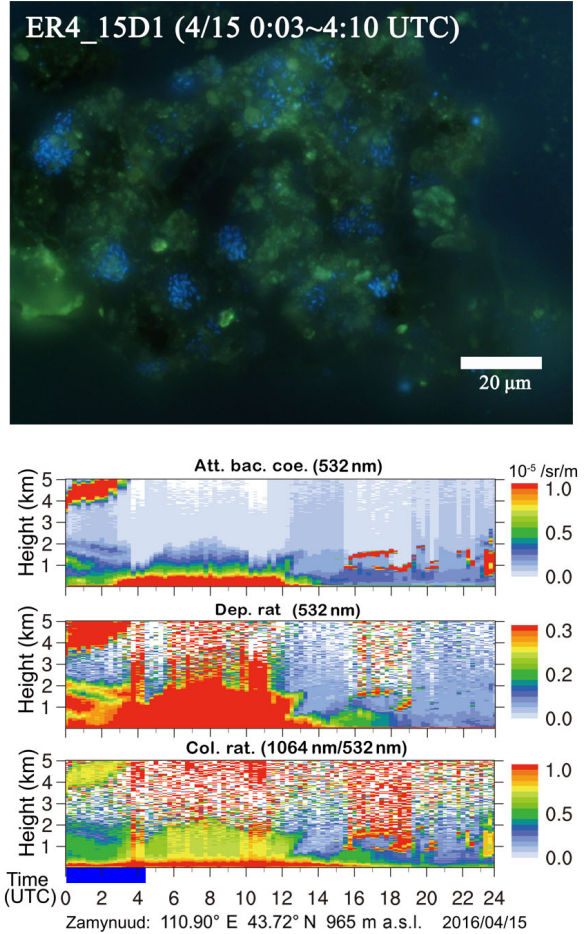

(b)
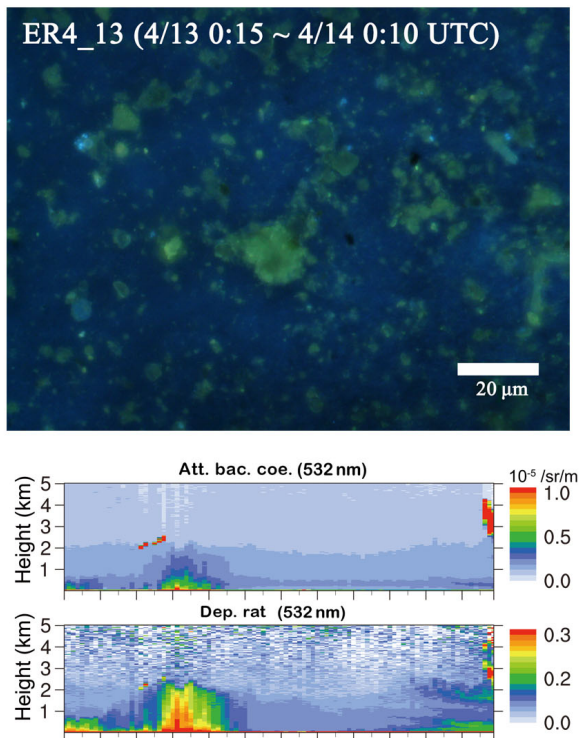

Col. rat. $(1064 \mathrm{~nm} / 532 \mathrm{~nm})$

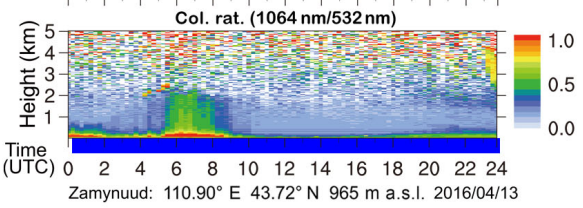

(d)
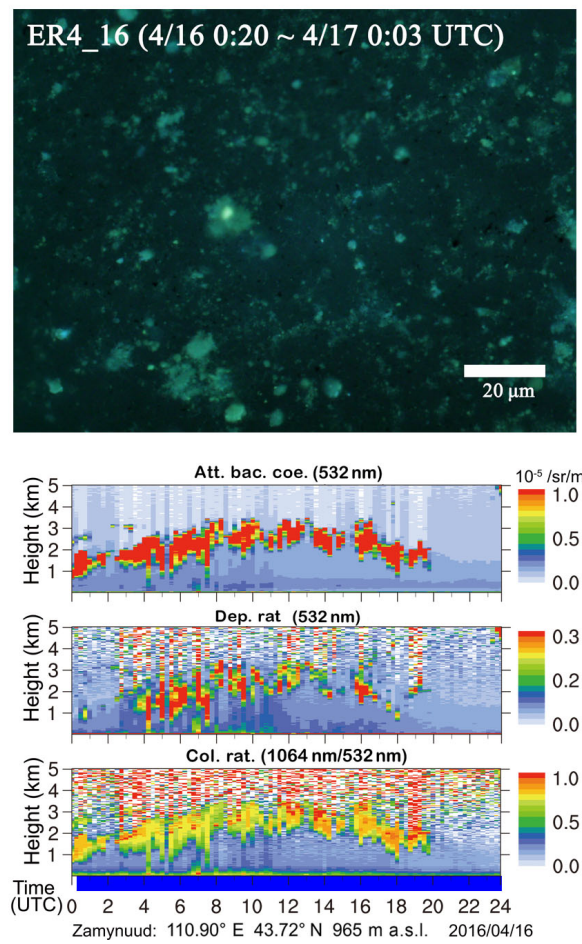

Figure 6. Comparisons of bioaerosols collected during a dust event and a non-dust event (a, b) and during a dust event that transported dust over a long distance and a local dust event $(\mathbf{c}, \mathbf{d})$. Blue bars represent the periods over which samples were collected. 


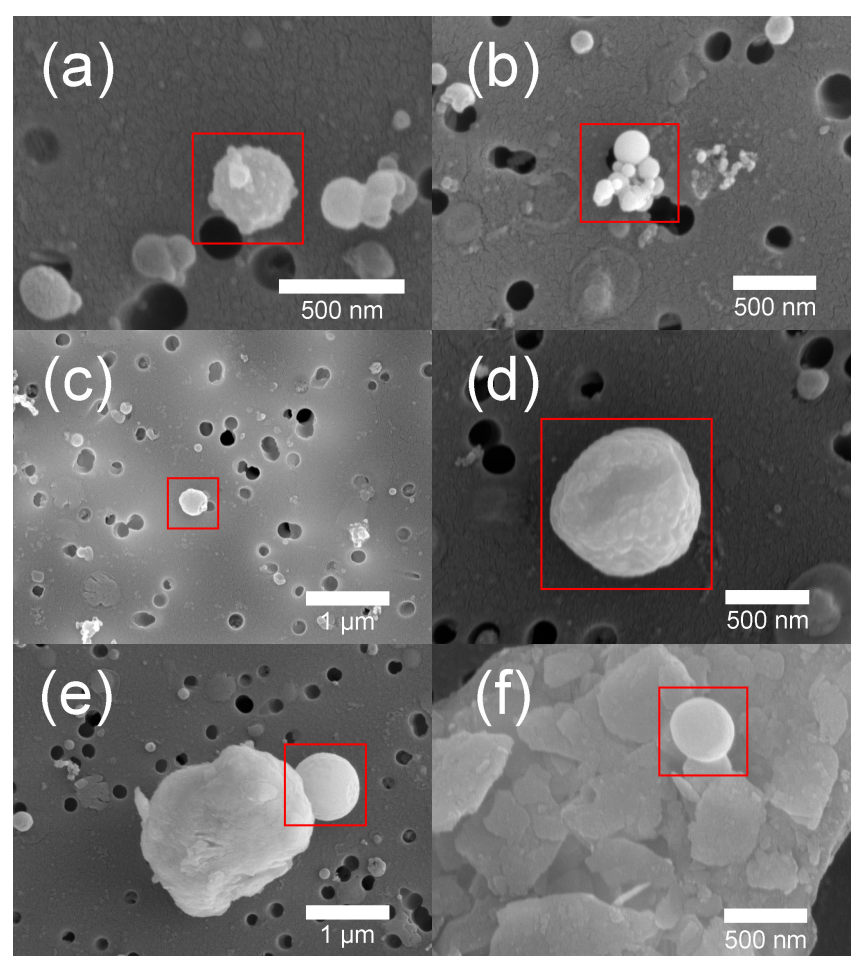

Figure 7. State of bioaerosols under SEM. All of the pictures depict non-dust samples collected in Erenhot; panel (a) shows ER4_11N, whereas the others are from ER4_9.

and Zhang, 2012) and showed relative correlation with $\mathrm{PM}_{10}$, which is an indicator of dust occurrences (Dong et al., 2016; Cha et al., 2016, 2017). In this study, the concentrations of the DAPI-stained bacteria, the white particles, and the yellow particles in the dust samples were significantly higher than those in the non-dust samples, whereas the concentrations of the black particles (black carbon) showed no obvious pattern regardless of the occurrence of dust events (Fig. 8a, $\mathrm{b}$, and $\mathrm{c}$ ). In general, the concentrations of DAPI-stained bacteria in the non-dust samples were on the order of $10^{4}$ to $10^{5}$ particles $\mathrm{m}^{-3}$, whereas those in the dust samples were $10^{5}$ to $10^{6}$ particles $\mathrm{m}^{-3}$. These concentrations are similar to the results of other field observations made in Tsogt-Ovoo in the Gobi Desert (Maki et al., 2016) and indicate that dust events can carry abundant microbes. In addition, the concentrations of the yellow particles in the non-dust and dust samples were on the order of $10^{5}$ to $10^{6}$ particles $\mathrm{m}^{-3}$ and $10^{6}$ to $10^{7}$ particles $\mathrm{m}^{-3}$, respectively. Aerosols transported by Asian dust events are reported to include high amounts of organic molecules, such as mannitol, glucose, and fructose, which consist of the cell components of airborne microorganisms (Fu et al., 2016). Similarly, the concentrations of the yellow particles (organic matter) and the white particles (mineral particles) increased with the concentrations of DAPI-stained bacteria (Fig. 9a), whereas the concentrations of the black particles showed no obvious pattern (Fig. 9a and b). These observations indicate that a close relationship existed among DAPI-stained bacteria, organic matter, and mineral particles. It is speculated that the yellow particles (organic matter) and the white particles (mineral particles) serve as nutrients and shelter for microbes, respectively, and favor their survival and long-distance transport. Some dead cells and debris from microbes are thought to also emit yellow fluorescence (Liu et al., 2014). Furthermore, the concentrations of the black particles decreased in some of the dust events (Fig. 8a), and the concentrations of the DAPI-stained bacteria and the yellow particles showed no obvious relationship with those of the black particles, whereas the concentrations of the white particles showed a declining trend with the increasing black particle concentrations (Fig. 9b). Thus, fewer black particles existed in the dust samples, and the black particles have little connection with the DAPI-stained bacteria and the yellow particles. These results are supported by other field observations in Tsogt-Ovoo in the Gobi Desert (Maki et al., 2016).

The concentration ratios of the DAPI-stained bacteria, the black particles, and the white particles to the yellow particles were calculated (Fig. 10). The concentration ratios of the DAPI-stained bacteria, the black particles, and the white particles to the yellow particles ranged from $5.1 \% \pm 6.3 \%$ (non-dust samples) to $9.8 \% \pm 6.3 \%$ (dust samples), from $73.6 \% \pm 100.4 \%$ (non-dust samples) to $9.0 \% \pm 8.2 \%$ (dust samples), and from $2.7 \% \pm 3.3 \%$ (non-dust samples) to $3.8 \% \pm 4.1 \%$ (dust samples), respectively (Fig. 10b). The concentration ratios of the DAPI-stained bacteria to the yellow particles were much higher in the dust samples than in the non-dust samples, while the concentration ratios of the black particles to the yellow particles significantly decreased in the dust samples in comparison to the non-dust samples. Thus, greater numbers of bacteria can be contained in a unit of yellow particles during dust events, whereas the black particles displayed the opposite behavior. The results indicate that the yellow particles (organic matter) in the dust may serve as nutrients and favor microbial survival and longdistance transport, which was also partly confirmed by the micrographs (Fig. 6a, b, c, and d). In contrast, the anthropogenic black carbon load in the dust samples decreased significantly compared to non-dust samples.

\subsection{Alpha and beta diversity analysis of the samples}

The 16S rDNA sequences from 22 samples were divided into 28949 OTUs (sequences with $>97 \%$ similarity), and the number of OTUs contained in these samples ranged from 150 to 3147 (Fig. 11a). The ITS rDNA sequences from 18 of the samples were divided into 223 OTUs, and the number of OTUs contained in these samples ranged from 5 to 74 (Fig. 11b). Phylogenetic assignment of the $16 \mathrm{~S}$ rDNA sequences resulted in an overall diversity profile that included bacteria and archaea, 34 phyla and candidate divisions, 94 classes (and class-level candidate taxa), 


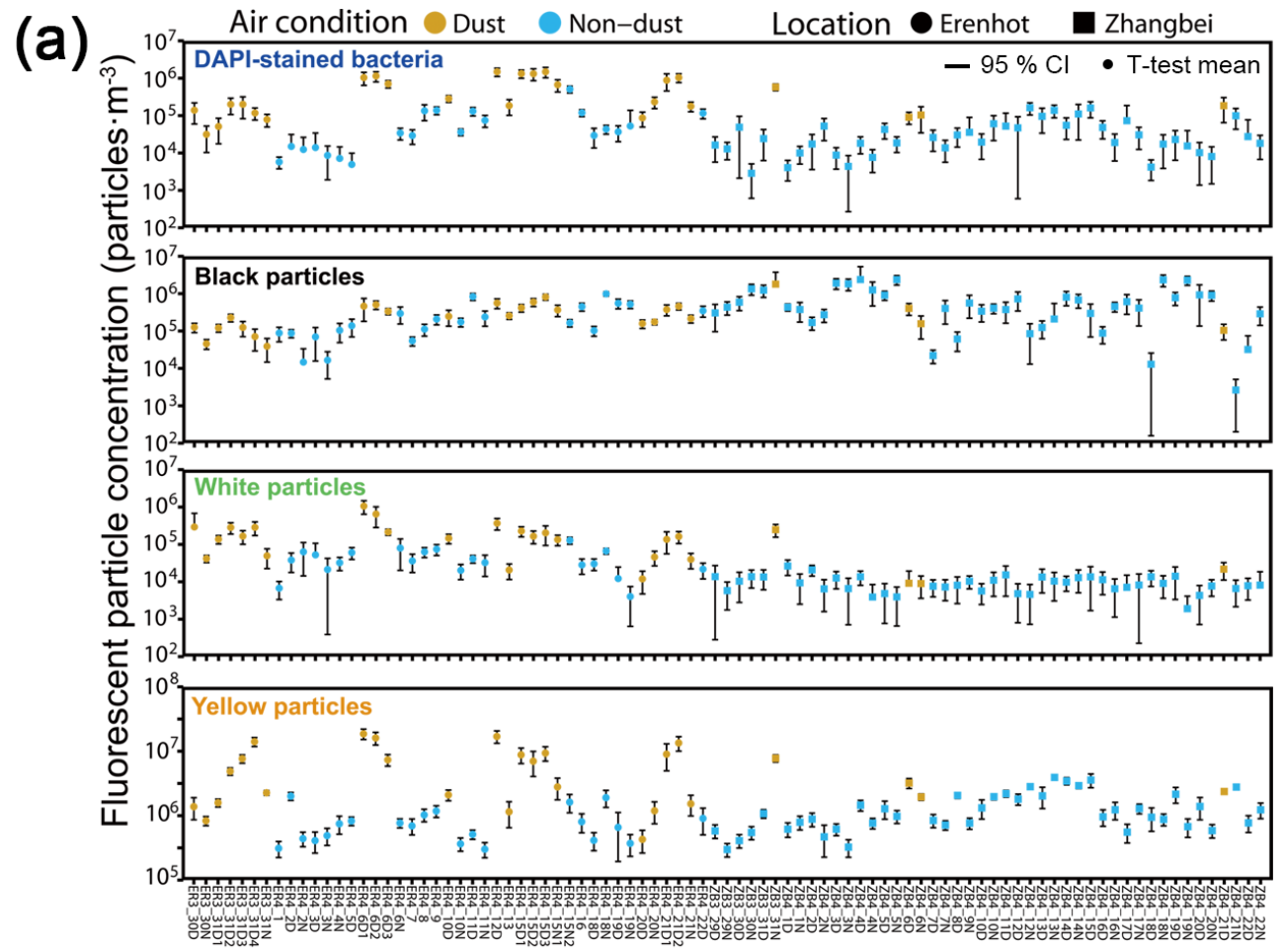

\section{Samples}

(b)

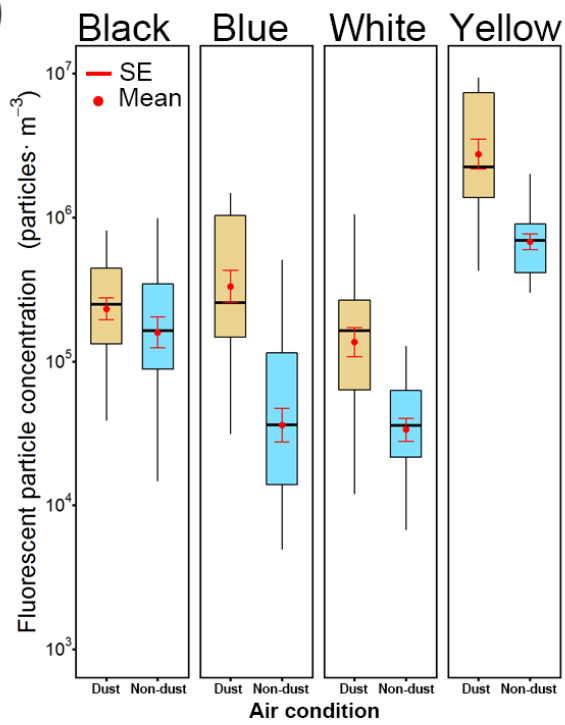

(c)

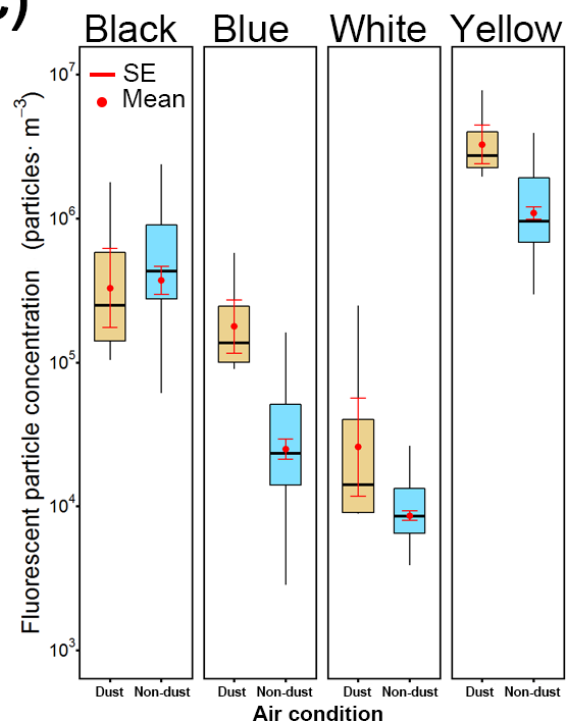

Figure 8. Changes in the concentrations of fluorescent particles in the samples (a) and a comparison of the concentrations of fluorescent particles in the samples collected during dust events and non-dust events in Erenhot (b) and Zhangbei (c) (black: black particles, blue: DAPI-stained bacteria, white: white particles, yellow: yellow particles, CI: confidence interval, SE: standard error).

166 orders (and order-level candidate taxa), and 243 families (and family-level candidate taxa). Phylogenetic assignment of the ITS rDNA sequences resulted in an overall diversity profile that included 3 phyla (Ascomycota, Basidiomycota, and Chytridiomycota), 19 classes (and class-level candidate taxa), 62 orders (and order-level candidate taxa), and
149 families (and family-level candidate taxa). Overall, the alpha diversity of the bacteria in the dust samples was higher than that of non-dust samples collected in Erenhot (Fig. 12a), whereas the alpha diversity of the fungi was much lower and showed no obvious pattern between the dust and non-dust samples (Fig. 12b). The results from another study in South 

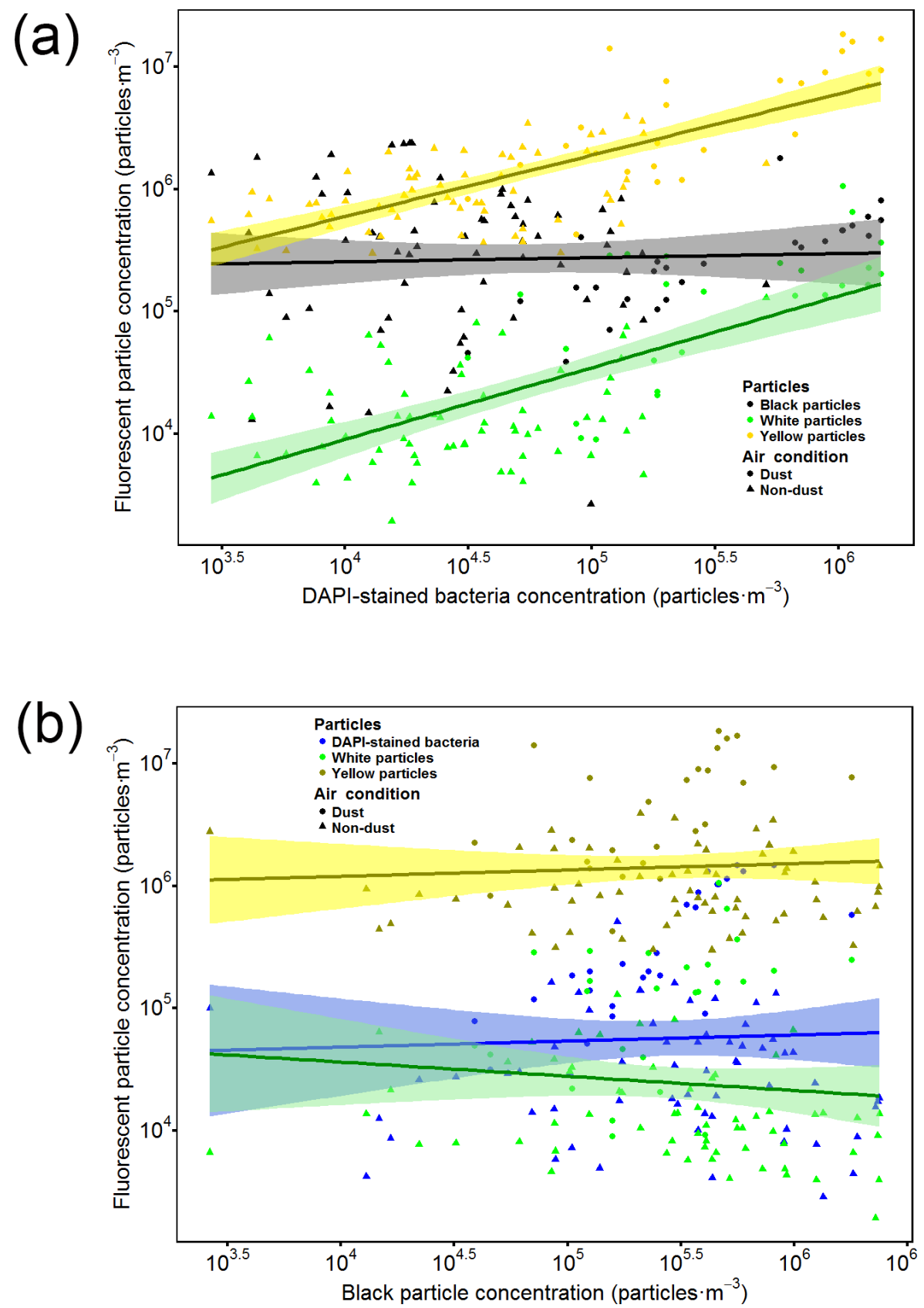

Figure 9. Changes in the concentrations of the other three kinds of fluorescent particles with the concentrations of DAPI-stained bacteria (a) and the concentrations of black particles (b) in the dust and non-dust samples.

Korea also suggest that airborne bacterial diversity (at least the richness index) increased during Asian dust events (Cha et al., 2016). It illustrates that the dust events can carry not only a huge number of bacteria, but also a great variety.

To analyze similarities in the bacterial community contained in each sample, principal coordinate analysis (PCoA) with weighted UniFrac distances was carried out. The sample Dz5_5R100 was discarded before PCoA analysis due to the small number of OTUs it contained (Fig. 11a). The re- sults show that the dust and non-dust samples from Erenhot displayed a distinct separation (Fig. 13), which indicates that the bacterial community composition differed significantly between the dust and non-dust samples. Similarly, the distinct clustering of prokaryotic communities separating the dust and non-dust samples of Tsogt-Ovoo was found in another study (Maki et al., 2016). The dust samples collected in Erenhot showed a high degree of similarity with the samples of R-DzToUb, which suggests that some types of bac- 

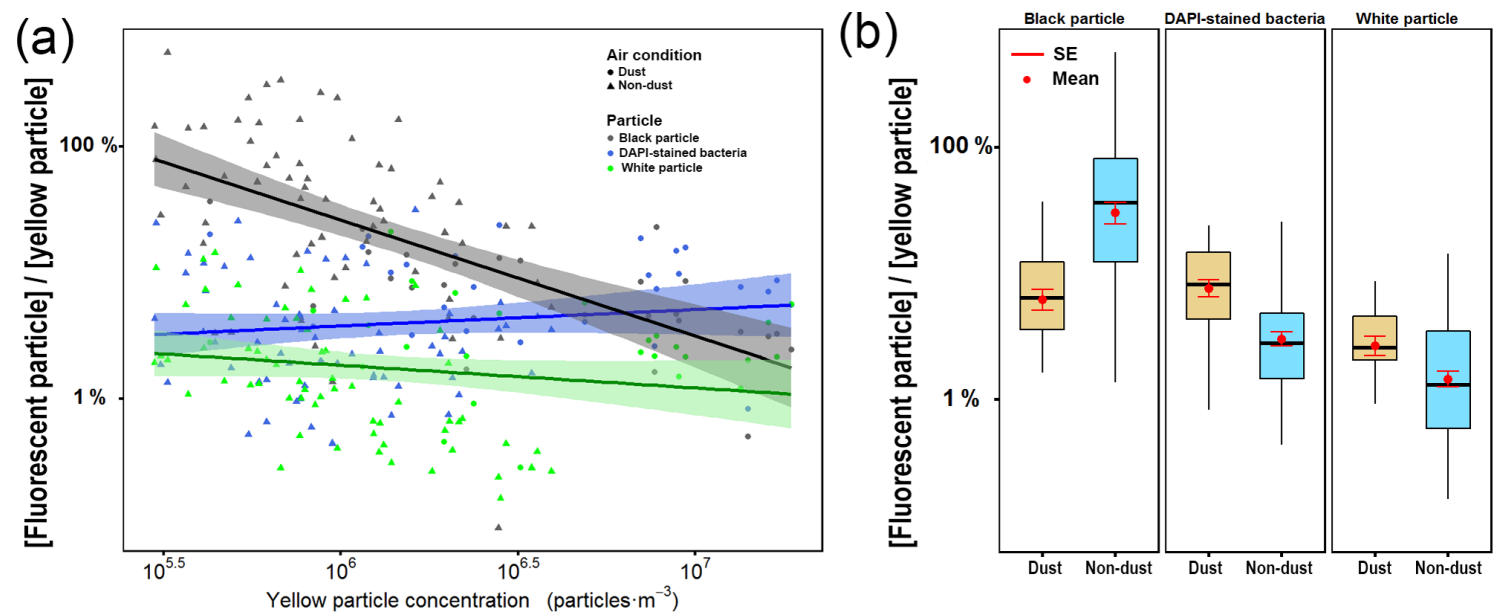

Figure 10. The concentration ratios of the other three kinds of fluorescent particles to the yellow particles (a) and a comparison of these ratios in the dust and non-dust samples (b) (SE: standard error; the $y$ axis is spaced logarithmically).

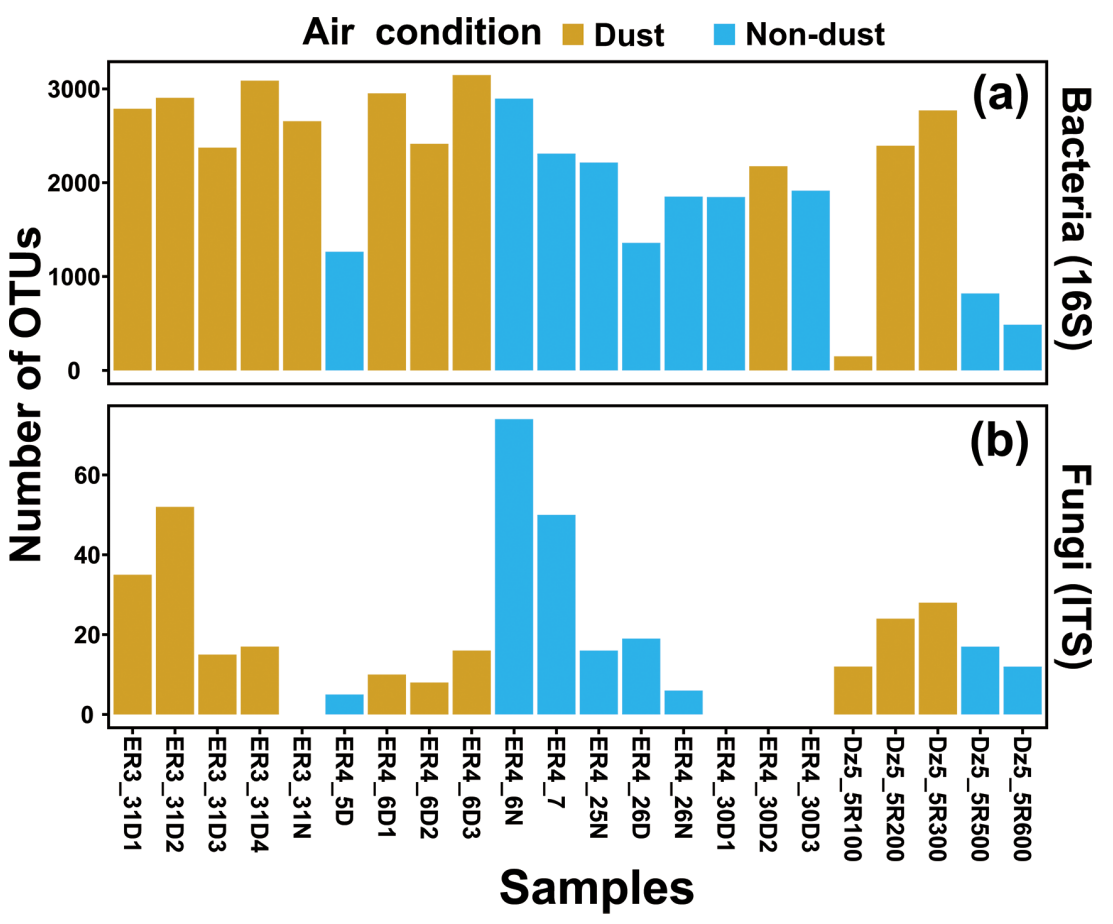

Figure 11. Number of OTUs for bacteria (a) and fungi (b).

teria were transported from the Gobi Desert of Mongolia to Erenhot.

\subsection{Analysis of the microbial community composition in the dust events and non-dust events}

Comparative analysis of the bacterial community composition revealed that the ubiquitous bacterial phyla in the samples were Acidobacteria, Actinobacteria, Bacteroidetes, Chloroflexi, Firmicutes, Gemmatimonadetes, and Proteobacteria (Fig. S5), which are typically the most abundant phyla in the atmospheric environment of the Gobi Desert (Maki et al., 2016). Of these phyla, Actinobacteria, Bacteroidetes, and Proteobacteria remained the dominant phyla in all the samples (Fig. 14).

At the phylum level, as for Erenhot, the relative abundances of Acidobacteria and Chloroflexi in the dust samples had a remarkable rise compared with the non-dust samples, followed by Crenarchaeota, Firmicutes, and Proteobacteria (Figs. 14a, b and S5a). By contrast, the opposite phenomenon appeared in R-DzToUb, and the relative abundances of Acidobacteria and Chloroflexi in the non-dust samples were 
(a) Bacteria (16S)

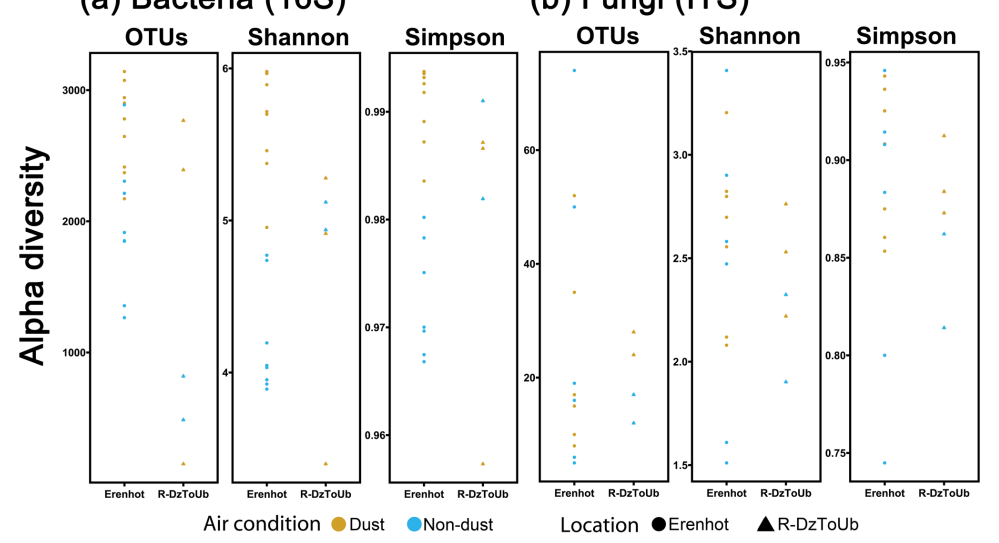

Figure 12. Alpha diversity of bacteria (a) and fungi (b) (OTUs: number of OTUs, Shannon: Shannon index, Simpson: Simpson index).

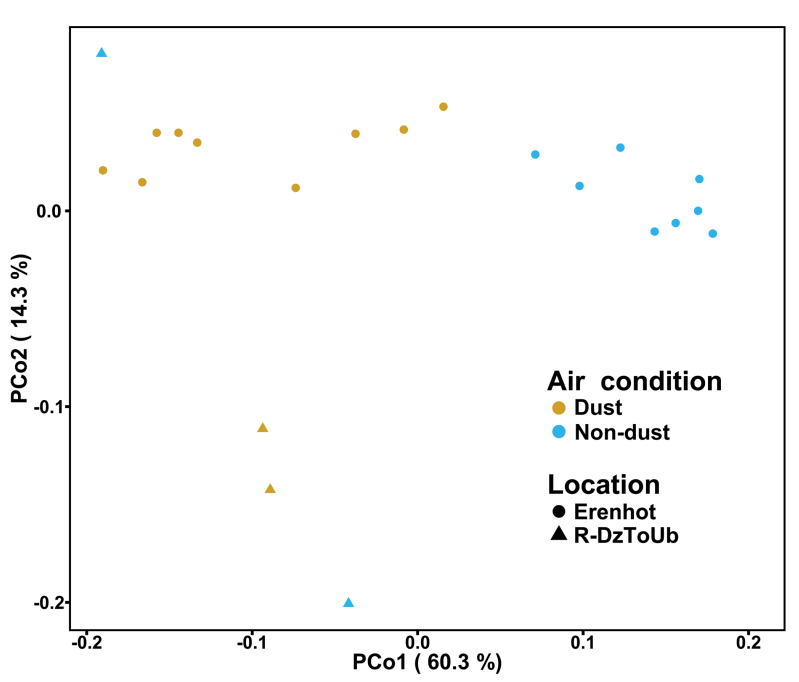

Figure 13. Principal coordinate analysis of bacterial 16S rRNA sequencing data obtained from 22 samples (PCo: principal coordinate).

greater than those in the dust samples (Fig. 14c and d). It is worth noting that all samples (dust and non-dust samples) of R-DzToUb were collected on the road from Dalanzadgad to Ulaanbaatar; small dust events continuously occurred there and some residue of dust particles would remain in the air for a longer period. The class Chloroflexi was dominant among the members of this phylum (Figs. 14 and 15). Notably, the phylum Chloroflexi includes six classes, of which only the class Chloroflexi consists of phototrophic bacteria. This phototrophic group, called filamentous anoxygenic phototrophic bacteria, shares the following features in common: multicellular filamentous morphology, gliding motility, and anoxygenic photosynthetic activity (Hanada, 2014). This phototrophic group can obtain light energy and maintain their survival in the air by using the light for photosynthesis. The long-distance transmission of such a group is possible.

The relative abundance of Proteobacteria in all dust samples increased slightly compared with non-dust samples, and Alphaproteobacteria made the major contribution among this group; by contrast, Gammaproteobacteria was just the reverse (Figs. 14 and 15). This suggests that the relative abundance of Alphaproteobacteria in the dust was higher than that in the air. These bacteria could help to identify the mixture levels of air masses transported for long distances, even the relative contributions of local sources and remote sources (particularly deserts) to the concentration of airborne biological particles in different regions (Maki et al., 2017).

The relative abundance of Firmicutes increased slightly in the dust samples compared with the non-dust samples (Fig. 14). Firmicutes was the predominant phylum of surface sand samples in the Gobi Desert, but not in the Taklamakan Desert (An et al., 2013). The relative abundance of Firmicutes can reach as high as $82 \%$ in surface sand samples from the Gobi Desert $\left(44.3^{\circ} \mathrm{N}, 110.1^{\circ} \mathrm{E}\right.$; An et al., 2013), but it was found in relatively small proportions that did not exceed $5 \%$ in all the air samples (Fig. 14). Maki et al. (2016) found that the relative abundance of Firmicutes in air samples from the Gobi Desert $\left(44.2304^{\circ} \mathrm{N}, 105.1700^{\circ} \mathrm{E}\right)$ varied greatly, from 15.7 to $40.5 \%$ in non-dust samples and no more than $12 \%$ in dust samples. The sequences of Firmicutes mainly belonged to the classes Bacilli and Clostridia in air samples from Tsogt-Ovoo, Mongolia (Maki et al., 2016), while Bacilli, Clostridia, and Erysipelotrichi in the phylum Firmicutes were found in the air samples from Erenhot (Fig. S5). The averaged relative abundance of Bacilli in dust samples from Erenhot was $3.2 \%$, while it is much lower in nondust samples (Fig. 15). It is worth mentioning that Zhu et al. (2018) found that the averaged relative abundance of Firmicutes in cloud samples at Mt. Tai in China was $80.5 \%$. As for the Taklimakan Desert, Puspitasari et al. (2015) analyzed the bacterial diversity in sand dunes and dust aerosol, and the 
(a)

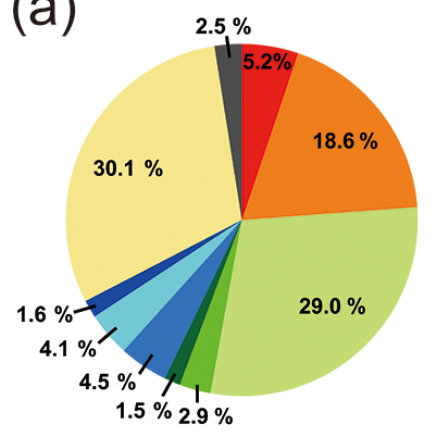

(c)

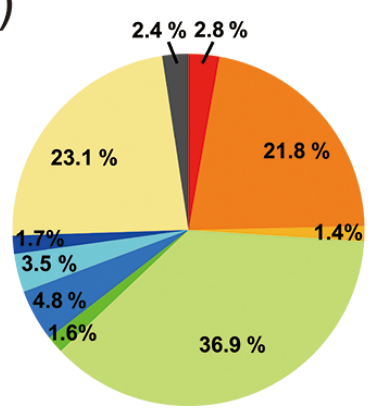

(b)

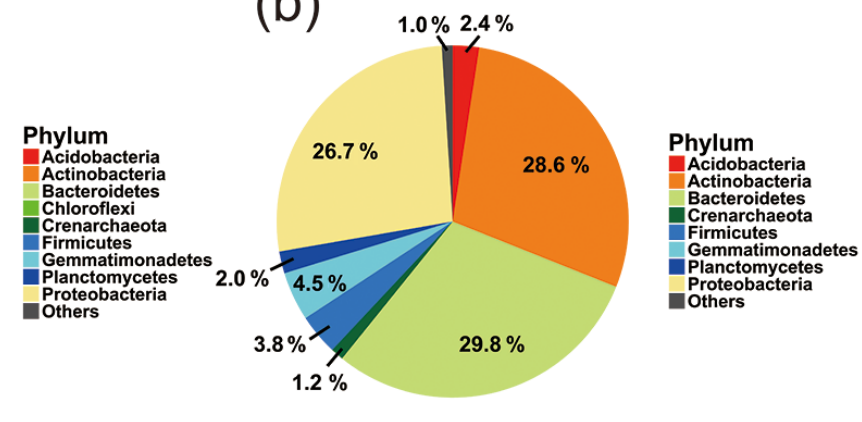

(d)

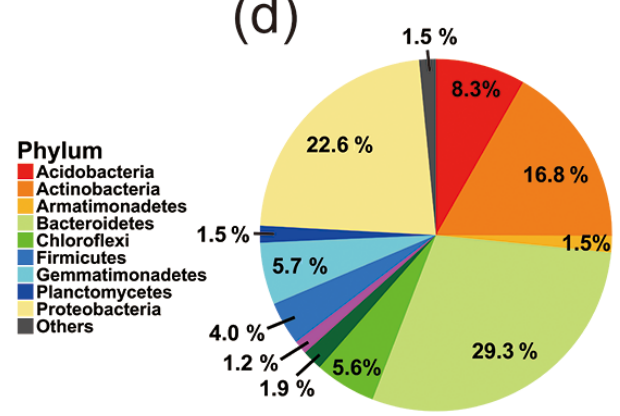

Phylum

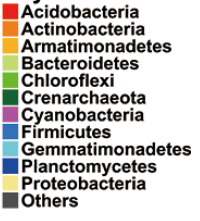

Figure 14. Variations in the bacterial community composition at the phylum level in (a) dust samples of Erenhot, (b) non-dust samples of Erenhot, (c) dust samples of R-DzToUb, and (d) non-dust samples of R-DzToUb.

(a)

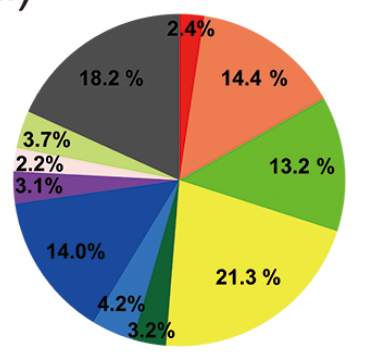

(c)

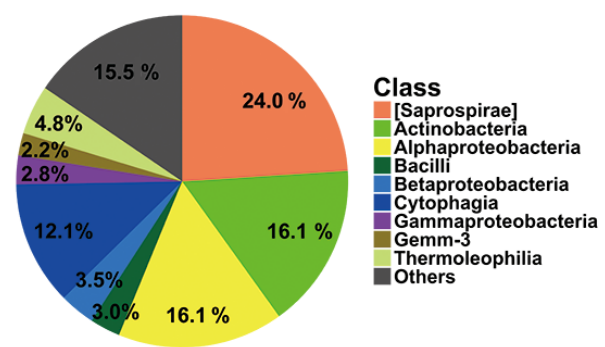

(b)

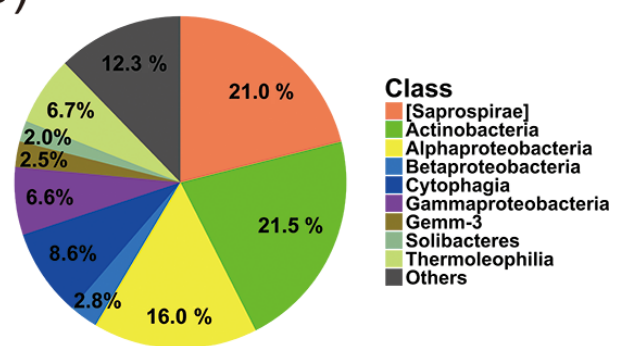

(d)

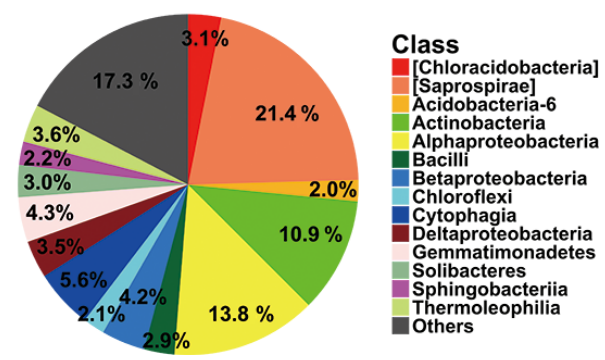

Figure 15. Variations in the bacterial community composition at the class level in (a) dust samples of Erenhot, (b) non-dust samples of Erenhot, (c) dust samples of R-DzToUb, and (d) non-dust samples of R-DzToUb. 

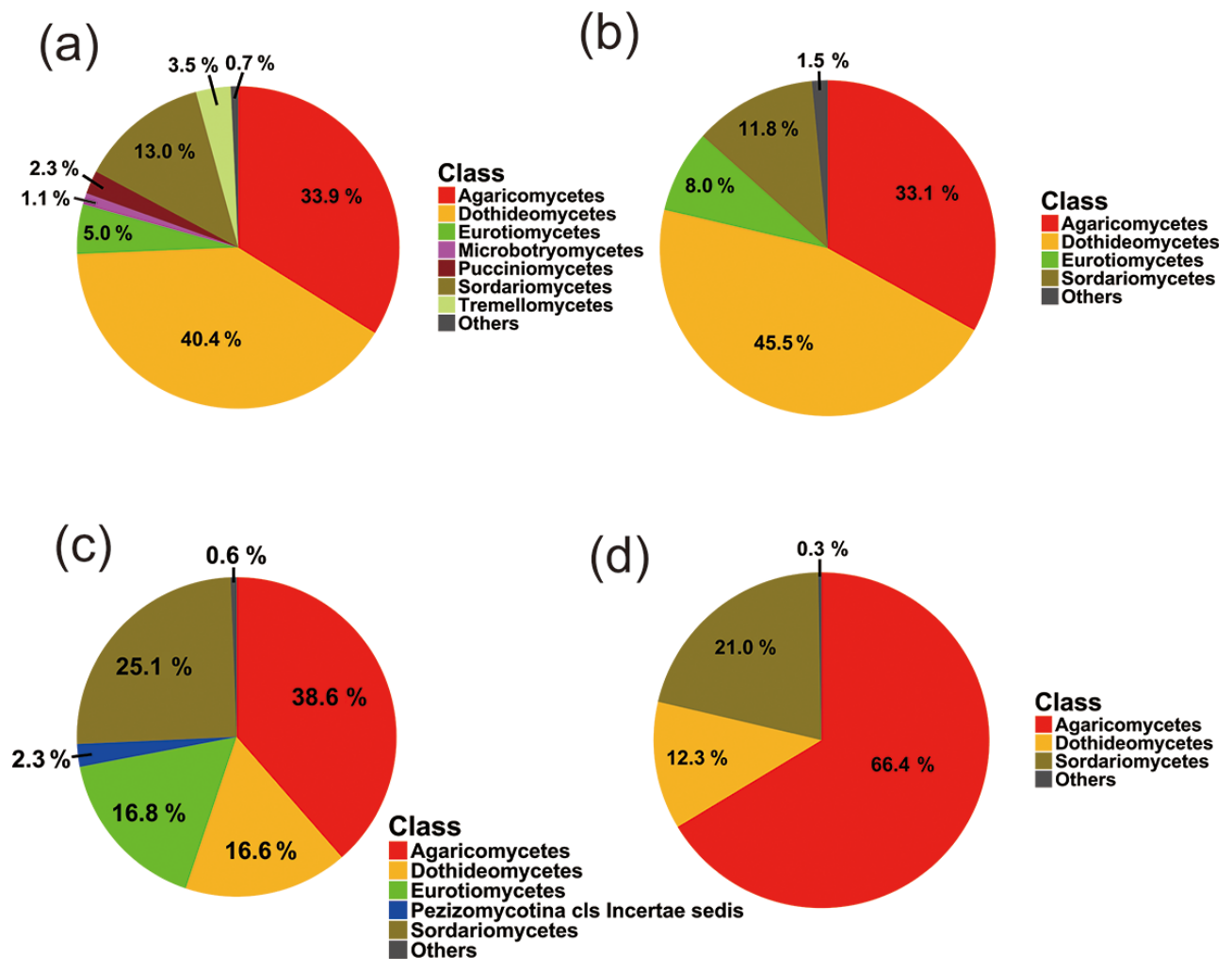

Figure 16. Variations in the fungal community composition at the class level in (a) dust samples of Erenhot, b) non-dust samples of Erenhot, (c) dust samples of R-DzToUb, and (d) non-dust samples of R-DzToUb.

relative abundance of Firmicutes in dust aerosol samples was higher than that in surface sand samples, which shows a different pattern compared to the Gobi Desert. In conclusion, the bacterial community compositions in the air are different from those in the surface sand or soil and differ by location and transmitting vector.

In addition, two phyla in the archaea kingdom, Crenarchaeota (which contains Thaumarchaeota at the class level) and Euryarchaeota (which contains Methanobacteria, Thermoplasmata, Methanomicrobia, and Halobacteria), were detected, but their relative abundances were much lower compared to the dominant bacterial phyla. Particularly, Thaumarchaeota was found only in the samples ER3_31N (heavy dust event) and Dz5_5R600 (the dust source region) in proportions exceeding $2 \%$ (Fig. S5). These bacteria could be used as tracers of air masses during dust events, even used to distinguish the dust that has been transported over a long distance from local dust.

The predominant fungal phyla were Ascomycota (mainly Dothideomycetes and Sordariomycetes) and Basidiomycota (mainly Agaricomycetes), and there was also a much lower relative abundance of Chytridiomycota (Fig. S6). There is no obvious pattern of the predominant fungal phyla in the dust and non-dust samples. At the class level, Agaricomycetes, Dothideomycetes, and Sordariomycetes were predominant, and the dust samples contained more diverse fungal classes than the non-dust samples (Fig. 16). As for Erenhot, the relative abundances of Microbotryomycetes, Pucciniomycetes, and Tremellomycetes in the dust samples increased significantly compared with those in the non-dust samples. While the relative abundance of Eurotiomycetes in the dust samples of R-DzToUb had a remarkable boom, that of Agaricomycetes almost halved in the dust samples compared to the non-dust samples there. In conclusion, there were obvious differences in the fungal community compositions between the dust and non-dust samples, and the changing pattern may be diversiform within different locations.

\section{Conclusions}

During the DuBi-2016 Campaign, bioaerosol samples were continuously collected along the transport path of Asian dust, and the effects of dust events originating in the Gobi Desert on the amount and diversity of bioaerosols were investigated. The concentrations of DAPI-stained bacteria in the dust samples can reach 2 orders of magnitude greater than those observed in the non-dust samples and 3 orders of magnitude greater for the yellow particles (organic matter). In addition, the alpha diversity of the bacteria in the dust samples was also greater than that noted in the non-dust samples. In conclusion, both the number of bacteria and the diversity of the 
bacterial communities increased significantly during the dust events, as determined by means of microscopic observations made with DAPI staining and MiSeq sequencing analysis. The results indicate that dust events can carry a surprising number of highly diverse microbes to downwind regions, and this transport may have potentially important impacts on local ecological environments and climate change.

Although deserts likely play a less important role as a source of biological matter to the atmosphere than biologically active regions, the atmospheric residence time of particles emitted from deserts is much longer than that of most other source regions as a result of the combination of strong dry convection and a lack of removal by precipitation in desert regions (Burrows et al., 2009; Schulz et al., 1998). So bioaerosols in desert dust particles are more likely to participate in long-distance transport and be observed in other regions. During the long-distance transport period, airborne microbes employ diverse strategies to adapt to the harsh atmospheric environment and maintain their viability. Microbial activities, including reproductive activity, may take place in the air, as was partly established by microscopic and SEM observations. Reproductive activity increases the number of microbes in the air, which may lead to an underestimation of the concentrations of microbes. Some activities may change the physicochemical properties of other atmospheric components, such as secondary organic aerosols, thereby changing their capacity to serve as ice nuclei (INs) or cloud condensation nuclei (CCNs), their radiative properties, and their other characteristics.

The predominant bacterial phyla found in the air samples were Actinobacteria, Bacteroidetes, and Proteobacteria. Many bacterial members can enter the atmosphere with the aid of wind. Some bacterial members display no resistance to the harsh environmental stressors in the atmosphere and are mostly eliminated; on the other hand, the remainder can be transported over long distances on the wind and have long-term impacts on ecological environments and climate change. Firmicutes provide a good example; they were found in large proportions that may even reach $82 \%$ at the surface of the Gobi Desert. However, most of them were eliminated by environmental stressors, and only a small fraction remained; the relative abundance in the air was less than $5 \%$. Moreover, the relative abundances of some bacterial members and fungal members increased markedly, together with the higher alpha diversity in dust samples than that in nondust samples, which contributed to a high diversity of the bacterial community in the downwind atmosphere, potentially representing a threat to local ecological environments.

Naturally, the dust and non-dust samples could be clearly separated from each other due to the different compositions of the bacterial communities they contained. In addition, some bacteria and fungi were only found in the dust samples. These taxa may originate in the dust source regions and can be used for provenance tracking, particularly to distinguish dust transported over long distances from local dust.
Bioaerosols originating from Asian desert areas have a high possibility to disperse to downwind regions, such as Korea and Japan, by the prevailing westerly winds in the middle latitudes (Iwasaka et al., 2009) and are sometimes carried to the Pacific Ocean (Smith et al., 2013). Huge dust events create an atmospheric bridge over land and sea, which may contribute to the biodiversity on the earth, but the impact of bioaerosols transported over long distances should be checked carefully.

Although the amount and diversity of bioaerosols in the air have been investigated, the viability and activity of airborne microbes, the interactions between bioaerosols and other gaseous and solid components in the air, and the effects of bioaerosols on animals and plants, the ecological environment, and the climate system require in-depth study to permit a detailed understanding of bioaerosols in the air.

Data availability. Lidar data of Zamyn-Üüd were provided by courtesy of AD-Net (http://www-lidar.nies.go.jp/AD-Net, Shimizu et al., 2016). The $72 \mathrm{~h}$ back trajectories of air masses in Zhangbei calculated using the HYSPLIT mode (http://www.arl.noaa.gov/ HYSPLIT). All the data obtained from MiSeq sequencing have been deposited in the DDBJ/EMBL/GenBank database, and the accession number of the submission is PRJNA413598.

\section{The Supplement related to this article is available online at https://doi.org/10.5194/acp-18-7131-2018-supplement.}

Competing interests. The authors declare that they have no conflict of interest.

Special issue statement. This article is part of the special issue "Anthropogenic dust and its climate impact". It does not belong to a conference.

Acknowledgements. This research was supported by the National Natural Science Foundation of China (41575017, 41375031, 41521004, 41405113, and 41505011), a China 111 project (B 13045), the Fundamental Research Funds for the Central Universities (lzujbky-2017-k03 and lzujbky-2017-it21), and the Key Laboratory for Semi-Arid Climate Change of the Ministry of Education at Lanzhou University. This study was also supported by Grants-in-Aid for Scientific Research A (no. 17H01616) and B (no. 26304003) from the Japan Society for the Promotion of Science (JSPS). The employees of Fasmac Co., Ltd. assisted in the MiSeq sequencing analyses. Air mass trajectories were reconstructed using the NOAA ARL website (http://ready.arl.noaa.gov; last access: 18 September 2017). We wish to thank the Electron Microscopy Center of Lanzhou University for the microscopy and microanalysis of our specimens. 
Edited by: Kenji Kai

Reviewed by: Kevin Lee and two anonymous referees

\section{References}

Amato, P., Joly, M., Schaupp, C., Attard, E., Möhler, O., Morris, C. E., Brunet, Y., and Delort, A. M.: Survival and ice nucleation activity of bacteria as aerosols in a cloud simulation chamber, Atmos. Chem. Phys., 15, 6455-6465, https://doi.org/10.5194/acp15-6455-2015, 2015.

An, S., Couteau, C., Luo, F., Neveu, J., and DuBow, M. S.: Bacterial diversity of surface sand samples from the Gobi and Taklamaken deserts, Microb. Ecol., 66, 850-860, https://doi.org/10.1007/s00248-013-0276-2, 2013.

Bi, J., Huang, J., Holben, B., and Zhang, G.: Comparison of key absorption and optical properties between pure and transported anthropogenic dust over East and Central Asia, Atmos. Chem. Phys., 16, 15501-15516, https://doi.org/10.5194/acp-16-155012016, 2016.

Bi, J., Huang, J., Shi, J., Hu, Z., Zhou, T., Zhang, G., Huang, Z., Wang, X., and Jin, H.: Measurement of scattering and absorption properties of dust aerosol in a Gobi farmland region of northwestern China - A potential anthropogenic influence, Atmos. Chem. Phys., 17, 7775-7792, https://doi.org/10.5194/acp17-7775-2017, 2017.

Bory, A. J.-M., Biscaye, P. E., and Grousset, F. E.: Two distinct seasonal Asian source regions for mineral dust deposited in Greenland (NorthGRIP), Geophys. Res. Lett., 30, 149-153, https://doi.org/10.1029/2002GL016446, 2003.

Brown, J. K. M. and Hovmøller, M. S.: Aerial Dispersal of Pathogens on the Global and Continental Scales and Its Impact on Plant Disease, Science, 297, 537-541, https://doi.org/10.1126/science.1072678, 2002.

Burrows, S. M., Elbert, W., Lawrence, M. G., and Pöschl, U.: Bacteria in the global atmosphere - Part 2: Modeling of emissions and transport between different ecosystems, Atmos. Chem. Phys., 9, 9263-9280, https://doi.org/10.5194/acp-9-9263-2009, 2009.

Caporaso, J. G., Lauber, C. L., Walters, W. A., Berg-Lyons, D., Lozupone, C. A., Turnbaugh, P. J., Fierer, N., and Knight, R.: Global patterns of $16 \mathrm{~S}$ rRNA diversity at a depth of millions of sequences per sample, P. Natl. Acad. Sci. USA, 108, 4516-4522, https://doi.org/10.1073/pnas.1000080107, 2011.

Cha, S., Lee, D., Jang, J. H., Lim, S., Yang, D., and Seo, T.: Alterations in the airborne bacterial community during Asian dust events occurring between February and March 2015 in South Korea, Sci. Rep., 6, 1-9, https://doi.org/10.1038/srep37271, 2016.

Cha, S., Srinivasan, S., Jang, J. H., Lee, D., Lim, S., Kim, K. S., Jheong, W., Lee, D. W., Park, E. R., Chung, H. M., Choe, J., Kim, M. K., and Seo, T.: Metagenomic analysis of airborne bacterial community and diversity in seoul, korea, during December 2014, asian dust event, PLoS One, 12, 1-12, https://doi.org/10.1371/journal.pone.0170693, 2017.

Chen, S., Huang, J., Li, J., Jia, R., Jiang, N., Kang, L., Ma, X., and Xie, T.: Comparison of dust emissions, transport, and deposition between the Taklimakan Desert and Gobi Desert from 2007 to 2011, Sci. China Earth Sci., 60, 1338-1355, https://doi.org/10.1007/s11430-016-9051-0, 2017.
Creamean, J. M., Suski, K. J., Rosenfeld, D., Cazorla, A., Demott, P. J., Sullivan, R. C., White, A. B., Ralph, F., Minnis, P., Comstock, J. M., Tomlinson, J. M., and Prather, K. A.: Dust and Biological Aerosols from the Sahara and Asia Influence Precipitation in the Western US, Science, 339, 1572-1578, https://doi.org/10.1126/science.1227279, 2013.

DeLeon-Rodriguez, N., Lathem, T. L., Rodriguez, R. L., Barazesh, J. M., Anderson, B. E., Beyersdorf, A. J., Ziemba, L. D., Bergin, M., Nenes, A., and Konstantinidis, K. T.: Microbiome of the upper troposphere: species composition and prevalence, effects of tropical storms, and atmospheric implications, P. Natl. Acad. Sci. USA, 110, 2575-2580, https://doi.org/10.1073/pnas.1212089110, 2013.

Dong, L., Qi, J., Shao, C., Zhong, X., Gao, D., Cao, W., Gao, J., Bai, R., Long, G., and Chu, C.: Concentration and size distribution of total airborne microbes in hazy and foggy weather, Sci. Total Environ., 541, 1011-1018, https://doi.org/10.1016/j.scitotenv.2015.10.001, 2016.

Fröhlich-Nowoisky, J., Kampf, C. J., Weber, B., Huffman, J. A., Pöhlker, C., Andreae, M. O., Lang-Yona, N., Burrows, S. M., Gunthe, S. S., Elbert, W., Su, H., Hoor, P., Thines, E., Hoffmann, T., Després, V. R., and Pöschl, U.: Bioaerosols in the Earth System: Climate, Health, and Ecosystem Interactions, Atmos. Res., 182, 346-376, https://doi.org/10.1016/j.atmosres.2016.07.018, 2016.

Fu, P. Q., Zhuang, G. S., Sun, Y. L., Wang, Q. Z., Chen, J., Ren, L. J., Yang, F., Wang, Z. F., Pan, X. L., Li, X. D., and Kawamura, K.: Molecular markers of biomass burning, fungal spores and biogenic SOA in the Taklimakan desert aerosols, Atmos. Environ., 130, 64-73, https://doi.org/10.1016/j.atmosenv.2015.10.087, 2016.

Griffin, D. W.: Atmospheric movement of microorganisms in clouds of desert dust and implications for human health, Clin. Microbiol. Rev., 20, 459-477, https://doi.org/10.1128/CMR.00039-06, 2007.

Grousset, F. E., Ginoux, P., Bory, A., and Biscaye, P. E.: Case study of a Chinese dust plume reaching the French Alps, Geophys. Res. Lett., 30, 23-26, https://doi.org/10.1029/2002GL016833, 2003.

Hanada S.: The phylum Chloroflexi, the family Chloroflexaceae, and the related phototrophic families Oscillochloridaceae and Roseiflexaceae: The Prokaryotes, Springer, Berlin Heidelberg, Germany, 515-532, 2014.

Hara, K. and Zhang, D.: Bacterial abundance and viability in long-range transported dust, Atmos. Environ., 47, 20-25, https://doi.org/10.1016/j.atmosenv.2011.11.050, 2012.

Hervàs, A., Camarero, L., Reche, I., and Casamayor, E. O.: Viability and potential for immigration of airborne bacteria from Africa that reach high mountain lakes in Europe, Environ. Microbiol., 11, 1612-1623, https://doi.org/10.1111/j.14622920.2009.01926.x, 2009.

Ho, H. M., Rao, C. Y., Hsu, H. H., Chiu, Y. H., Liu, C. M., and Chao, H. J.: Characteristics and determinants of ambient fungal spores in Hualien, Taiwan, Atmos. Environ., 39, 5839-5850, https://doi.org/10.1016/j.atmosenv.2005.06.034, 2005.

Hua, N. P., Kobayashi, F., Iwasaka, Y., Shi, G. Y., and Naganuma, T.: Detailed identification of desert-originated bacteria carried by Asian dust storms to Japan, Aerobiologia (Bologna), 23, 291298, https://doi.org/10.1007/s10453-007-9076-9, 2007. 
Huang, J., Minnis, P., Chen, B., Huang, Z., Liu, Z., Zhao, Q., Yi, Y., and Ayers, J. K.: Long-range transport and vertical structure of Asian dust from CALIPSO and surface measurements during PACDEX, J. Geophys. Res.-Atmos., 113, 1-13, https://doi.org/10.1029/2008JD010620, 2008a.

Huang, J., Zhang, W., Zuo, J., Bi, J., Shi, J., Wang, X., Chang, Z., Huang, Z., Yang, S., Zhang, B., Wang, G., Feng, G., Yuan, J., Zhang, L., Zuo, H., Wang, S., Fu, C., and Chou, J.: An overview of the semi-arid climate and environment research observatory over the Loess Plateau, Adv. Atmos. Sci., 25, 906-921, https://doi.org/10.1007/s00376-008-0906-7, 2008b.

Huang, J., Fu, Q., Zhang, W., Wang, X., Zhang, R., Ye, H., and Warren, S. G.: Dust and black carbon in seasonal snow across Northern China, B. Am. Meteorol. Soc., 92, 175-181, https://doi.org/10.1175/2010BAMS3064.1, 2011.

Huang, J., Yu, H., Guan, X., Wang, G., and Guo, R.: Accelerated dryland expansion under climate change, Nature Climate Change, 6, 166-171, https://doi.org/10.1038/nclimate2837, 2015.

Huang, J., Li, Y., Fu, C., Chen, F., Fu, Q., Dai, A., Shinoda, M., Ma, Z., Guo, W., Li, Z., Zhang, L., Liu, Y., Yu, H., He, Y., Xie, Y., Guan, X., Ji, M., Lin, L., Wang, S., Yan, H., and Wang, G.: Dryland Climate Change: Recent Progress and Challenges, Rev. Geophys., 55, 1-60, https://doi.org/10.1002/2016RG000550, 2017a.

Huang, J., Yu, H., Dai, A., Wei, Y., and Kang, L.: Drylands face potential threat under $2{ }^{\circ} \mathrm{C}$ global warming target, Nature Climate Change, 7, 417-422, https://doi.org/10.1038/nclimate3275, $2017 b$.

Huang, Z., Huang, J., Bi, J., Wang, G., Wang, W., Fu, Q., Li, Z., Tsay, S.-C., and Shi, J.: Dust aerosol vertical structure measurements using three MPL lidars during 2008 China-US joint dust field experiment, J. Geophys. Res., 115, D00K15, https://doi.org/10.1029/2009JD013273, 2010.

Huang, Z., Huang, J., Hayasaka, T., Wang, S., Zhou, T., and Jin, H.: Short-cut transport path for Asian dust directly to the Arctic: a case study, Environ. Res. Lett., 10, 114018, https://doi.org/10.1088/1748-9326/10/11/114018, 2015.

Husar, R. B., Tratt, D. M., Schichtel, B. A., Falke, S. R., Li, F., Jaffe, D., Gill, T., Laulainen, N. S., Lu, F., Reheis, M. C., Chun, Y., Westphal, D., Mckendry, I., Kuring, N., Feldman, G. C., Frouin, R. J., Merrill, J., Dubois, D., Vignola, F., Murayama, T., Nickovic, S., Wilson, W. E., Sassen, K., Sugimoto, N., and Malm, W. C.: Asian dust events of April 1998, J. Geophys. Res.-Atmos., 106, 18317-18330, https://doi.org/10.1029/2000JD900788, 2001.

Ichinose, T., Nishikawa, M., Takano, H., Sera, N., Sadakane, K., Mori, I., Yanagisawa, R., Oda, T., Tamura, H., Hiyoshi, K., Quan, H., Tomura, S., and Shibamoto, T.: Pulmonary toxicity induced by intratracheal instillation of Asian yellow dust (Kosa) in mice, Env. Toxicol. Pharmacol., 20, 48-56, https://doi.org/10.1016/j.etap.2004.10.009, 2005.

Iwasaka, Y., Hiroaki, M., and Nagaya, K.: The transport and spatial scale of Asian dust storm clouds: a case study of the dust storm event of April 1979, Tellus B, 35, 189-196, https://doi.org/10.3402/tellusb.v35i3.14594, 1983.

Iwasaka, Y., Shi, G. Y., Yamada, M., Kobayashi, F., Kakikawa, M., Maki, T., Naganuma, T., Chen, B., Tobo, Y., and Hong, C. S.: Mixture of Kosa (Asian dust) and bioaerosols detected in the at- mosphere over the Kosa particles source regions with balloonborne measurements: possibility of long-range transport, Air Qual. Atmos. Heal., 2, 29-38, https://doi.org/10.1007/s11869009-0031-5, 2009.

Jeon, E. M., Kim, H. J., Jung, K., Kim, J. H., Kim, M. Y., Kim, Y. P., and Ka, J.-O.: Impact of Asian dust events on airborne bacterial community assessed by molecular analyses, Atmos. Environ., 45, 4313-4321, https://doi.org/10.1016/j.atmosenv.2010.11.054, 2011.

Jeon, E. M., Kim, Y. P., Jeong, K., Kim, I. S., Eom, S. W., Choi, Y. Z., and Ka, J. O.: Impacts of Asian dust events on atmospheric fungal communities, Atmos. Environ., 81, 39-50, https://doi.org/10.1016/j.atmosenv.2013.08.039, 2013.

Jorquera, H., Borzutzky, A., Hoyos-Bachiloglu, R., and García, A.: Association of Kawasaki disease with tropospheric winds in Central Chile: Is wind-borne desert dust a risk factor?, Environ. Int., 78, 32-38, https://doi.org/10.1016/j.envint.2015.02.007, 2015.

Liu, B., Ichinose, T., He, M., Kobayashi, F., Maki, T., Yoshida, S., Yoshida, Y., Arashidani, K., Takano, H., Nishikawa, M., Sun, G., and Shibamoto, T.: Lung inflammation by fungus, Bjerkandera adusta isolated from Asian sand dust (ASD) aerosol and enhancement of ovalbumin-induced lung eosinophilia by ASD and the fungus in mice, Allergy Asthma. Clin. Immunol., 10, 1-12, https://doi.org/10.1186/1710-1492-10-10, 2014.

Lozupone, C., Lladser, M. E., Knights, D., Stombaugh, J., and Knight, R.: UniFrac: An effective distance metric for microbial community comparison, ISME J., 5, 169-172, https://doi.org/10.1038/ismej.2010.133, 2011.

Lozupone, C. A., Hamady, M., Kelley, S. T., and Knight, R.: Quantitative and qualitative - diversity measures lead to different insights into factors that structure microbial communities, Appl. Environ. Microbiol., 73, 1576-1585, https://doi.org/10.1128/AEM.01996-06, 2007.

Maki, L. R. and Willoughby, K. J.: Bacteria as Biogenic Sources of Freezing Nuclei, J. Appl. Meteorol., 17, 1049-1053, https://doi.org/10.1175/15200450(1978)017<1049:BABSOF>2.0.CO;2, 1978.

Maki, T., Susuki, S., Kobayashi, F., Kakikawa, M., Yamada, M., Higashi, T., Chen, B., Shi, G., Hong, C., Tobo, Y., Hasegawa, H., Ueda, K., and Iwasaka, Y.: Phylogenetic diversity and vertical distribution of a halobacterial community in the atmosphere of an Asian dust (KOSA) source region, Dunhuang City, Air Qual. Atmos. Hlth., 1, 81-89, https://doi.org/10.1007/s11869-008-00169, 2008.

Maki, T., Puspitasari, F., Hara, K., Yamada, M., Kobayashi, F., Hasegawa, H., and Iwasaka, Y.: Variations in the structure of airborne bacterial communities in a downwind area during an Asian dust (Kosa) event, Sci. Total Environ., 488/489, 75-84, https://doi.org/10.1016/j.scitotenv.2014.04.044, 2014.

Maki, T., Hara, K., Kobayashi, F., Kurosaki, Y., Kakikawa, M., Matsuki, A., Chen, B., Shi, G., Hasegawa, H., and Iwasaka, Y.: Vertical distribution of airborne bacterial communities in an Asiandust downwind area, Noto Peninsula, Atmos. Environ., 119, 282-293, https://doi.org/10.1016/j.atmosenv.2015.08.052, 2015.

Maki, T., Kurosaki, Y., Onishi, K., Lee, K. C., Pointing, S. B., Jugder, D., Yamanaka, N., Hasegawa, H., and Shinoda, M.: Variations in the structure of airborne bacterial communities in Tsogt-Ovoo of Gobi desert area during dust events, Air Qual. 
Atmos. Hlth., 10, 249-260, https://doi.org/10.1007/s11869-0160430-3, 2016.

Maki, T., Hara, K., Iwata, A., Lee, K. C., Kawai, K., Kai, K., Kobayashi, F., Pointing, S. B., Archer, S., Hasegawa, H., and Iwasaka, Y.: Variations in airborne bacterial communities at high altitudes over the Noto Peninsula (Japan) in response to Asian dust events, Atmos. Chem. Phys., 17, 11877-11897, https://doi.org/10.5194/acp-17-11877-2017, 2017.

Nishizawa, T., Sugimoto, N., Matsui, I., Shimizu, A., Hara, Y., Itsushi, U., Yasunaga, K., Kudo, R., and Kim, S. W.: Groundbased network observation using Mie-Raman lidars and multiwavelength Raman lidars and algorithm to retrieve distributions of aerosol components, J. Quant. Spectrosc. Ra., 188, 79-93, https://doi.org/10.1016/j.jqsrt.2016.06.031, 2016.

Park, J., Ichijo, T., Nasu, M., and Yamaguchi, N.: Investigation of bacterial effects of Asian dust events through comparison with seasonal variability in outdoor airborne bacterial community, Sci. Rep., 6, 35706, https://doi.org/10.1038/srep35706, 2016.

Prospero, J. M., Blades, E., Mathison, G., and Naidu, R.: Interhemispheric transport of viable fungi and bacteria from Africa to the Caribbean with soil dust, Aerobiologia (Bologna), 21, 119, https://doi.org/10.1007/s10453-004-5872-7, 2005.

Pu, W., Wang, X., Zhang, X., Ren, Y., Shi, J. Sen, Bi, J. R., and Zhang, B. D.: Size distribution and optical properties of particulate matter $\left(\mathrm{PM}_{10}\right)$ and black carbon $(\mathrm{BC})$ during dust storms and local air pollution events across a loess plateau site, Aerosol Air Qual. Res., 15, 2212-2224, https://doi.org/10.4209/aaqr.2015.02.0109, 2015.

Puspitasari, F., Maki, T., Shi, G., Bin, C., Kobayashi, F., Hasegawa, H., and Iwasaka, Y.: Phylogenetic analysis of bacterial species compositions in sand dunes and dust aerosol in an Asian dust source area, the Taklimakan Desert, Air Qual. Atmos. Heal., 9, 631-644, https://doi.org/10.1007/s11869-015-0367-y, 2015.

Rodo, X., Ballester, J., Cayan, D., Melish, M. E., Nakamura, Y., Uehara, R., and Burns, J. C.: Association of Kawasaki disease with tropospheric wind patterns, Sci. Rep., 1, 1-7, https://doi.org/10.1038/srep00152, 2011.

Schulz, M., Balkanski, Y. J., Guelle, W., and Dulac, F.: Role of aerosol size distribution and source location in a threedimensional simulation of a Saharan dust episode tested against satellite-derived optical thickness, J. Geophys. Res.-Atmos., 103, 10579-10592, https://doi.org/10.1029/97JD02779, 1998.

Shimizu, A., Nishizawa, T., Jin, Y., Kim, S.-W., Wang, Z., Batdorj, D., and Sugimoto, N.: Evolution of a lidar network for tropospheric aerosol detection in East Asia, Opt. Eng., 56, 31219, https://doi.org/10.1117/1.OE.56.3.031219, 2016.

Smets, W., Moretti, S., Denys, S., and Lebeer, S.: Airborne bacteria in the atmosphere: Presence, purpose, and potential, Atmos. Environ., 139, 214-221, https://doi.org/10.1016/j.atmosenv.2016.05.038, 2016.

Smith, D. J., Timonen, H. J., Jaffe, D. A., Griffin, D. W., Birmele, M. N., Perry, K. D., Ward, P. D., and Roberts, M. S.: Intercontinental dispersal of bacteria and archaea by transpacific winds, Appl. Environ. Microbiol., 79, 1134-1139, https://doi.org/10.1128/AEM.03029-12, 2013.

Sugimoto, N. and Huang, Z.: Lidar methods for observing mineral dust, J. Meteor. Res., 28, 173-184, https://doi.org/10.1007/s13351-014-3068-9, 2014.
Sugimoto, N., Huang, Z., Nishizawa, T., Matsui, I., and Tatarov, B.: Fluorescence from atmospheric aerosols observed with a multichannel lidar spectrometer, Opt. Express, 20, 20800-20807, 2012.

Tong, Y. and Lighthart, B.: The annual bacterial particle concentration and size distribution in the ambient atmosphere in a rural area of the Willamette Valley, Oregon, Aerosol Sci. Technol., 32, 393-403, https://doi.org/10.1080/027868200303533, 2000.

Uno, I., Eguchi, K., Yumimoto, K., Takemura, T., Shimizu, A., Uematsu, M., Liu, Z., Wang, Z., Hara, Y., and Sugimoto, N.: Asian dust transported one full circuit around the globe, Nat. Geosci., 2, 557-560, https://doi.org/10.1038/ngeo583, 2009.

Wang, G., Huang, J., Guo, W., Zuo, J., Wang, J., Bi, J., Huang, Z., and Shi, J.: Observation analysis of land-atmosphere interactions over the Loess Plateau of northwest China, J. Geophys. Res.-Atmos., 115, 1-15, https://doi.org/10.1029/2009JD013372, 2010.

Wang, X., Xu, B., and Ming J.: An Overview of the Studies on Black Carbon and Mineral Dust Deposition in Snow and Ice Cores in East Asia, J. Meteor. Res., 28, 354-370, https://doi.org/10.1007/s13351-014-4005-7, 2014.

Wang, X., Pu, W., Shi, J., Bi, J., Zhou, T., Zhang, X., and Ren, Y.: A comparison of the physical and optical properties of anthropogenic air pollutants and mineral dust over Northwest China, J. Meteor. Res., 29, 180-200, https://doi.org/10.1007/s13351-0154092-0, 2015.

Wang, X., Wen, H., Shi, J., Bi, J., Huang, Z., Zhang, B., Zhou, T., Fu, K., Chen, Q., and Xin, J.: Optical and microphysical properties of natural mineral dust and anthropogenic soil dust near dust source regions over northwestern China, Atmos. Chem. Phys., 18, 2119-2138, https://doi.org/10.5194/acp18-2119-2018, 2018.

Wu, P. C., Tsai, J. C., Li, F. C., Lung, S. C., and Su, H. J.: Increased levels of ambient fungal spores in Taiwan are associated with dust events from China, Atmos. Environ., 38, 4879-4886, https://doi.org/10.1016/j.atmosenv.2004.05.039, 2004.

Yamaguchi, N., Ichijo, T., Sakotani, A., Baba, T., and Nasu, M.: Global dispersion of bacterial cells on Asian dust, Sci. Rep., 2, 1-6, https://doi.org/10.1038/srep00525, 2012.

Yeo, H. G. and Kim, J. H.: SPM and fungal spores in the ambient air of west Korea during the Asian dust (Yellow sand) period, Atmos. Environ., 36, 5437-5442, https://doi.org/10.1016/S13522310(02)00672-6, 2002.

Zhou, T., Huang, J., Huang, Z., Liu, J., Wang, C., and Lin, L.: The depolarization-attenuated backscatter relationship for dust plumes, Opt. Express, 13, 15195-15204, https://doi.org/10.1364/OE.21.015195, 2013.

Zhu, C., Chen, J., Wang, X., Li, J., Wei, M., Xu, C., Xu, X., Ding, A., and Collett, J. L.: Chemical composition and bacterial community in size-resolved cloud water at the summit of Mt. Tai, China, Aerosol Air Qual. Res., 18, 1-14, https://doi.org/10.4209/aaqr.2016.11.0493, 2018. 